Nova Southeastern University

\title{
Aerosol Properties and Chemical Apportionment of Aerosol Optical Depth at Locations off the U.S. East Coast in July and August 2001
}

Brian I. Magi

University of Washington - Seattle Campus

Peter V. Hobbs

University of Washington - Seattle Campus

Thomas W. Kirchstetter

Lawrence Berkeley National Laboratory

Tihomir Novakov

Lawrence Berkeley National Laboratory

Dean A. Hegg

University of Washington - Seattle Campus

See next page for additional authors

Follow this and additional works at: https://nsuworks.nova.edu/cnso_chemphys_facarticles Part of the Environmental Chemistry Commons

\section{NSUWorks Citation}

Magi, B. I., Hobbs, P. V., Kirchstetter, T. W., Novakov, T., Hegg, D. A., Gao, S., Redemann, J., \& Schmid, B. (2005). Aerosol Properties and Chemical Apportionment of Aerosol Optical Depth at Locations off the U.S. East Coast in July and August 2001. Journal of Atmospheric Science, 62, (4), 919 - 933. https://doi.org/10.1175/JAS3263.1. Retrieved from https://nsuworks.nova.edu/ cnso_chemphys_facarticles/150 
Authors

Brian I. Magi, Peter V. Hobbs, Thomas W. Kirchstetter, Tihomir Novakov, Dean A. Hegg, Song Gao, Jens Redemann, and Beat Schmid 


\title{
Aerosol Properties and Chemical Apportionment of Aerosol Optical Depth at Locations off the U.S. East Coast in July and August 2001
}

\author{
Brian I. Magi, $*$ Peter V. Hobbs, $*$ Thomas W. Kirchstetter, ${ }^{+}$Tihomir Novakov, ${ }^{+}$Dean A. Hegg,* \\ Song Gao,\# Jens Redemann, ${ }^{@}$ And Beat Schmid ${ }^{@}$ \\ *Department of Atmospheric Sciences, University of Washington, Seattle, Washington \\ ${ }^{+}$Lawrence Berkeley National Laboratory, Berkeley, California \\ \# Department of Chemistry, University of Washington, Seattle, Washington \\ ${ }^{@}$ Bay Area Environmental Research Institute, Sonoma, California
}

(Manuscript received 12 May 2003, in final form 28 October 2003)

\begin{abstract}
Airborne in situ measurements of vertical profiles of the aerosol light scattering coefficient, light absorption coefficient, and single scattering albedo $\left(\omega_{0}\right)$ are presented for locations off the East Coast of the United States in July-August 2001. The profiles were obtained in relatively clean air, dominated by airflows that had passed over Canada and the Atlantic Ocean. Comparisons of aerosol optical depths (AODs) at $550 \mathrm{~nm}$ derived from airborne in situ and sun-photometer measurements agree, on average, to within $0.034 \pm 0.021$. A frequency distribution of $\omega_{0}$ measured in the atmospheric boundary layer off the coast yields an average value of $\omega_{0}=$ $0.96 \pm 0.03$ at $550 \mathrm{~nm}$. Values for the mass scattering efficiencies of sulfate and total carbon (organic and black carbon) derived from a multiple linear regression are $6.0 \pm 1.0 \mathrm{~m}^{2}\left(\mathrm{~g} \mathrm{SO}_{4}^{=}\right)^{-1}$ and $2.6 \pm 0.9 \mathrm{~m}^{2}(\mathrm{~g} \mathrm{C})^{-1}$, respectively. Measurements of sulfate and total carbon mass concentrations are used to estimate the contributions of these two major components of the submicron aerosol to the AOD. Mean percentage contributions to the AOD from sulfate, total carbon, condensed water, and absorbing aerosols are $38 \% \pm 8 \%, 26 \% \pm 9 \%, 32 \% \pm$ $9 \%$, and $4 \% \pm 2 \%$, respectively. The sensitivity of the above results to the assumed values of the hygroscopic growth factors for the particles are examined and it is found that, although the AOD derived from the in situ measurements can vary by as much as $20 \%$, the average value of $\omega_{0}$ is not changed significantly. The results are compared with those obtained in the same region in 1996 under more polluted conditions.
\end{abstract}

\section{Introduction}

Anthropogenic aerosols play an important role in attenuating solar radiation as it passes through the atmosphere, which in turn affects the temperature of the earth (Houghton et al. 2001). The amount of attenuation depends on the light scattering and the light absorption coefficients (which together comprise the light extinction coefficient) of the constituent aerosols. Of particular importance for radiative transfer calculations are the aerosol single scattering albedo (i.e., the ratio of the light scattering coefficient to the light extinction coefficient) and the aerosol optical depth (AOD), which is the light extinction coefficient integrated over height. Chemical apportionments of AOD have been reported for rural and urban regions of the United States (White 1990), the Atlantic seaboard of the United States (Hegg et al. 1997), and Brisbane, Australia (Chan et al. 1999). In this paper we report a similar study for the U.S.

Corresponding author address: Peter V. Hobbs, Dept. of Atmospheric Sciences, University of Washington, Box 351640, Seattle, WA 98195-1640.

E-mail:phobbs@atmos.washington.edu central East Coast based on airborne measurements obtained in July-August 2001 during the Chesapeake Lighthouse and Aircraft Measurements for Satellites (CLAMS) field campaign.

\section{Instrumentation and methods}

Except for measurements of surface temperature and pressure, all of the measurements presented in this paper were obtained aboard the University of Washington's (UW) Convair-580 research aircraft. Table 1 lists the instruments aboard the Convair-580 relevant to this study. Brief descriptions of these instruments follow.

Aircraft altitude was determined by calculating the hypsometric altitude using onboard measurements of pressure and temperature combined with ground-based measurements of surface pressure and temperature from Wallops Island, Virginia. Aircraft altitude was also determined from an onboard global positioning system (GPS), although this suffered from periodic outages. When operational, the GPS altitude and the derived hypsometric altitude agreed to within $\sim 1 \%$ at $700 \mathrm{hPa}$. In all cases, altitude is reported as above mean sea level. Particle size distributions were measured with a par- 
ticle cavity aerosol spectrometer probe- $100 \times($ PCASP$100 \times$ ) located on the wing of the UW Convair-580. The sample chamber of the PCASP was heated, so that the size distribution of dry particles was measured. The PCASP was calibrated with nonabsorbing latex spheres, but the diameter limits of the bins were adjusted to an aerosol with a refractive index of $m=1.46-0.0086 i$, as recommended by Hartley et al. (2000). After the refractive index correction, the diameter range of the 15 bins of the PCASP was $0.11-4.5 \mu \mathrm{m}$.

The aerosol light scattering coefficient was measured with a nephelometer that was custom built for the UW by MS Electron; it is similar to the commercially available TSI nephelometer (e.g., Anderson and Ogren 1998). This nephelometer provided simultaneous measurements of the light scattering coefficient and hemispheric backscatter coefficient at three visible wavelengths $(450,550$, and $700 \mathrm{~nm}$, with a nominal 40-nm bandwidth). The airstream to the nephelometer was heated to dry the aerosol and thereby eliminate the effects of ambient relative humidity $(\mathrm{RH})$ on the measured aerosol light scattering and backscattering coefficients. Hartley et al. (2000) discuss details of the MS Electron (MS) nephelometer used by UW, the precision of the measurements $(\sim 10 \%)$, and the methods used in this study to correct the measurements for forward angular truncation and non-Lambertian illumination. The values outputted by the nephelometer were at ambient temperature and pressure. However, when comparing with mass concentrations of chemical species (described below), which were derived at standard temperature and pressure (STP), the nephelometer measurements were adjusted to STP.

Since the sample airstream to the nephelometer was dried to $\sim 30 \% \mathrm{RH}$, the effect of varying ambient $\mathrm{RH}$ (often much greater than $30 \% \mathrm{RH}$ ) on the light scattering coefficient of the ambient aerosol was determined using a hygroscopic growth function based on in situ measurements obtained in the same general geographical area as the present study (Kotchenruther et al. 1999). In section $4 \mathrm{~h}$, we examine the sensitivity of the optical properties of the ambient aerosol to the value of the hygroscopic growth factor.

The aerosol light absorption coefficient was measured at a wavelength of $567 \mathrm{~nm}$ (15-nm bandwidth) using the particle and soot absorption photometer (PSAP) described by Hartley et al. (2000). The airstream to the PSAP was heated to dry the aerosol. The precision of the PSAP measurements is $\sim 25 \%$, with larger percentage errors at lower values of light absorption. The PSAP provided 30-s running mean values of the light absorption coefficient of the dried aerosol with outputs every second. An internal flow meter in the PSAP monitored the flow rate at STP, but when the temperature and pressure differed from STP, the PSAP readings were adjusted to ambient temperature and pressure. The values of dry aerosol light absorption coefficient at ambient temperature and pressure were corrected for errors in 
the sample spot size, instrument-to-instrument variability, instrument noise, PSAP response to scattering, and PSAP response to absorption, following the procedures described by Bond et al. (1999), which implicity account for a wavelength adjustment from 567 to $550 \mathrm{~nm}$.

After applying the corrections discussed above, and when the air was very clean, the values of scattering and/or absorption sometimes bordered on the detection limit of the instruments. In these cases, the absorption values often exceeded the scattering values at points in the vertical profiles. In view of the relatively low concentrations of carbonaceous aerosol, the single scattering albedo was unlikely to have been below 0.85 . Therefore, we ignored values of absorption less than 3 per megameter $\left(\mathrm{Mm}^{-1}\right)$ when scattering values were less than $17 \mathrm{Mm}^{-1}$; these limits correspond to an aerosol single scattering albedo of 0.85 at $550 \mathrm{~nm}$.

For analyses of the total particulate mass and ionic species mass, aerosol samples were collected on filters using the baghouse system described by Magi and Hobbs (2003). When opened to the outside air, the baghouse sampled $2.5 \mathrm{~m}^{3}$ of ambient air in about $30 \mathrm{~s}$. Stainless steel holders for Teflon filters and quartz filters were attached to a flow meter manifold, which provided the filters with simultaneous samples of ambient air from the baghouse. Multiple baghouse samples were needed to ensure adequate filter loading for accurate analyses. After the aircraft landed, the filters were removed from the holders and stored prior to laboratory analysis. The Teflon filters were analyzed for ions, as described by Gao et al. (2003), and the quartz filters for carbon content as described by Kirchstetter et al. (2003).

The National Aeronautics and Space Administration (NASA) 14-channel Ames Airborne Tracking Sunphotometer (AATS-14) was mounted atop the UW Convair580 aircraft. Provided the solar disk was not obscured by cloud, the AATS-14 continuously recorded the total AOD above the altitude of the aircraft, which is referred to here as the "column AOD." The method of determining the column AOD from the sun photometer measurements is described by Schmid et al. (2000).

The vertical resolution of the in situ measurements was set in the postanalysis at $50 \mathrm{~m}$ for high aerosol loading (in situ AOD > 0.1) or $200 \mathrm{~m}$ for low aerosol loading (in situ AOD $<0.1$ ) for the aerosol parameters and the data from the AATS-14. The vertical resolution of the meteorological state parameters was set at $50 \mathrm{~m}$. Data were linearly interpolated between the vertical grid points to derive a full vertical profile.

\section{Sampling strategies, flights, and synoptic conditions}

The airborne measurements used in this study were obtained at various locations off the central East Coast of the United States, as the aircraft changed altitude from, on average, just above ground level $(0.17-\mathrm{km}$ altitude) to about $3.3-\mathrm{km}$ altitude. This altitude range gen- erally encompassed one or more shallow layers of polluted air. Table 2 lists the data, time, location, and airflows near the surface and aloft for each of the vertical profiles used in this study. The airflow was determined from 72-h modeled parcel back trajectories from the National Oceanic and Atmospheric Administration (NOAA) Hysplit analysis tool (see online, http:// www.arl.noaa.gov/ready/hysplit4.html). Generally, over the 72-h period prior to a flight, the sampled air parcels had been transported over large distances and were often subsiding.

\section{Results \\ a. Comparisons of airborne sun photometer and airborne in situ measurements of aerosol optical depths}

Various layer AOD closure studies have been reported previously. Hegg et al. (1997) and Hartley et al. (2000) present the results of such studies based on measurements obtained in 1996 during the Tropical Aerosol Radiative Forcing Observational Experiment (TARFOX) field project, which took place in the same region as the present study. The layer AODs derived from the in situ measurements in those two studies were, on average, $14 \% \pm 8 \%$ and $12 \% \pm 5 \%$, respectively, lower than the layer AODs measured by the airborne sun photometer. Remer et al. (1997) found that ground-based measurements of AOD made on the East Coast in July 1993 were nearly twice as large as AOD values derived from airborne in situ measurements; they attributed the difference to unmeasured aerosol layers aloft. In the Great Plains in 1997 and 1998, Kato et al. (2000) found that ground-based measurements of AOD compared well with values derived from airborne in situ measurements when the atmospheric RH was low, whereas the AOD derived from in situ measurements were $\sim 28 \%$ lower than those derived from ground-based measurements in higher RH cases. For data collected over the Atlantic Ocean (Canary Islands), Schmid et al. (2000) found that AODs from in situ airborne measurements generally did not agree with those measured by a sun photometer, possibly because particles were sampled through an inlet that was inadequate for sampling the large particles typical of marine and dusty air. In contrast, Magi et al. (2003) reported that in air masses in southern Africa dominated by small, biomass-burning aerosol and low RH, layer AODs derived from in situ measurements aboard the UW Convair-580, using the same instruments as those used to obtain the measurements discussed in the present paper, were only $4 \% \pm$ $6 \%$ lower than those measured with the sun photometer aboard the aircraft.

In the present study, the airborne AATS-14 sun photometer provided remote sensing measurements of the column AOD. In a rapid tight climb (or descent) of the aircraft, the difference in column AOD between any two altitudes provides the AOD between those two points, 


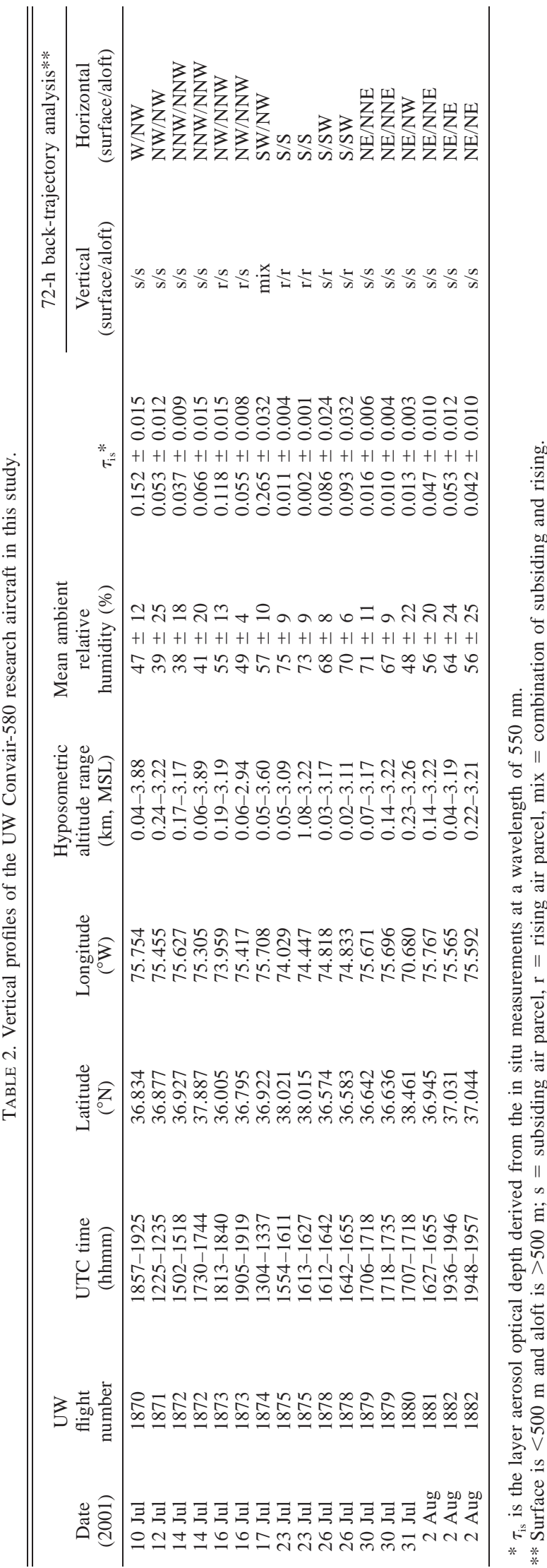

which we call the "layer AOD." We will refer to layer AODs measured by the sun photometer as $\tau_{\text {sun }}$.

The layer AOD between heights $z_{1}$ and $z_{2}\left(z_{1}<z_{2}\right)$ due to particles is given by

$$
\tau=\int_{z_{1}}^{z_{2}} \sigma_{\mathrm{ep}}(z) d z,
$$

where $\sigma_{\mathrm{ep}}(z)$ is the ambient light extinction coefficient due to particles at height $z$, and

$$
\sigma_{\mathrm{ep}}(z)=\sigma_{\mathrm{sp}}(z)+\sigma_{\mathrm{ap}}(z),
$$

where $\sigma_{\mathrm{sp}}(z)$ and $\sigma_{\mathrm{ap}}(z)$ are, respectively, the ambient light scattering and the ambient light absorption coefficients due to particles at altitude $z$. However, before the measured values of aerosol light scattering and light absorption coefficients can be substituted into (2), and then used in (1) to compute a layer AOD from the in situ measurements for comparison with the ambient AOD measured by the sun photometer, they must be multiplied by appropriate hygroscopic growth factors to account for the difference between the measurements, which were made at a $\mathrm{RH}$ of $\sim 30 \%$, and values at the ambient RH (the average ambient RH for the vertical profiles was about $60 \%$ ). Hence, the AOD between heights $z_{1}$ and $z_{2}$ from the in situ measurements $\left(\tau_{\text {is }}\right)$, when adjusted to the ambient $\mathrm{RH}$, is

$$
\tau_{\text {is }}=\int_{z_{1}}^{z_{2}}\left(\sigma_{\mathrm{spd}} f_{s}+\sigma_{\mathrm{apd}} f_{a}\right) d z,
$$

where $\sigma_{\text {spd }}$ is the dry light scattering coefficient due to particles, $\sigma_{\text {apd }}$ the dry light absorption coefficient due to particles, and $f_{s}$ and $f_{a}$ are the RH-dependent factors by which the dry scattering and absorption coefficients, respectively, must be multiplied to adjust their measured values to the ambient $\mathrm{RH}$.

Calculation of $\tau_{\text {is }}$ from (3) requires continuous measurements of $\sigma_{\text {spd }}, \sigma_{\text {apd }}, f_{s}$, and $f_{a}$ between $z_{1}$ and $z_{2}$. The values of $\sigma_{\mathrm{spd}}$ and $\sigma_{\mathrm{apd}}$ were measured, and we used values of $f_{s}$ as a function of RH (in percent) described by Kotchenruther et al. (1999); namely,

$$
f_{s}(\mathrm{RH})=\frac{1+a\left(\frac{\mathrm{RH}}{100}\right)^{b}}{1+a\left(\frac{30}{100}\right)^{b}},
$$

where $a=1.711 \pm 0.044$ and $b=3.41 \pm 0.16$ for airflow from the north or south, and $a=3.201 \pm 0.022$ and $b=3.78 \pm 0.04$ for airflow from the west. The values of $f_{a}$ are unknown, but are likely to lie between 1 and $f_{s}$ (Hegg et al. 1997; Redemann et al. 2001). Since $\sigma_{\text {apd }} \ll \sigma_{\text {spd }}$, we assume that $f_{a}=1$, which implies that $\sigma_{\text {apd }}=\sigma_{\text {ap }}$.

The common wavelength we use in comparing $\tau_{\text {sun }}$ with $\tau_{\text {is }}$ is $550 \mathrm{~nm}$, at which all wavelength-dependent 

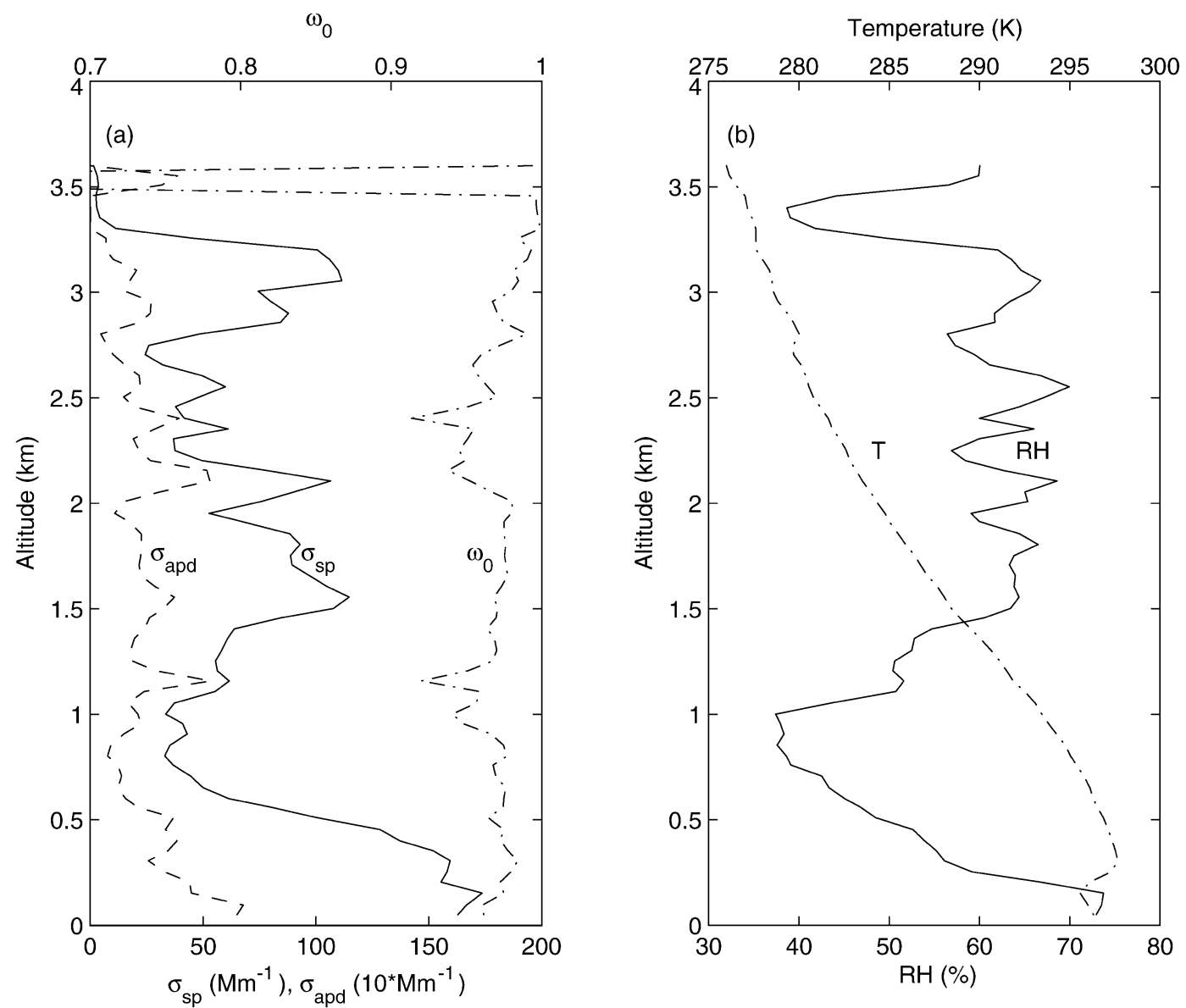

FIG. 1. Vertical profile from airborne in situ measurements of (a) the ambient aerosol light scattering coefficient $\left(\sigma_{\mathrm{sp}}\right)$, the dry aerosol light absorption coefficient $\left(\sigma_{\text {apd }}\right)$, and the aerosol single scattering albedo $\left(\omega_{0}\right)$ at $550 \mathrm{~nm}$, and (b) the relative humidity (RH) and temperature $(T)$, off the East Coast from 1304-1337 UTC on 17 Jul 2001 (UW flight 1874). The lower end of the scale for $\omega_{0}$ is terminated at 0.7 since values below this are subject to large errors.

values are reported in this study. The nephelometer provided measurements of $\sigma_{\text {spd }}$ at $550 \mathrm{~nm}$. The PSAP provides measurements of $\sigma_{\text {apd }}$ at $567 \mathrm{~nm}$, but these were adjusted to $550 \mathrm{~nm}$ as described in section 2 . The AATS14 sun photometer provided the column AOD at 13 discrete wavelengths from 354 to $1558 \mathrm{~nm}$; the closest wavelengths to $550 \mathrm{~nm}$ are 525 and $606 \mathrm{~nm}$. To derive a column AOD at $550 \mathrm{~nm}$ from the AATS-14 measurements, a quadratic polynomial interpolation equation described by Schmid et al. (2003) was used. The uncertainty in $\tau_{\text {sun }}$ is mainly due to potential horizontal variability (Redemann et al. 2005) in the atmosphere during a vertical profile. Methods used to quantify this potential uncertainty are described in Redemann et al. (2003).

A sample vertical profile of in situ measurements of $\sigma_{\text {sp }}, \sigma_{\text {apd }}$, the aerosol single scattering albedo $\left(\omega_{0}\right), \mathrm{RH}$, and temperature $(T)$ is shown in Fig. 1. The values of $\omega_{0}$ were calculated at a wavelength of $550 \mathrm{~nm}$ from

$$
\omega_{0}=\frac{\sigma_{\mathrm{sp}}}{\sigma_{\mathrm{sp}}+\sigma_{\mathrm{apd}}} .
$$

The measurements shown in Fig. 1 were obtained on 17 July 2001, when the aerosol loading was the highest encountered during the CLAMS field study. Features of the vertical profiles shown in Fig. 1 include a distinct temperature inversion at about $0.4 \mathrm{~km}$, and a mean $\mathrm{RH}$ of about $60 \%$ that clearly plays a role in the correlation between $\mathrm{RH}$ and the ambient light scattering coefficient $\sigma_{\text {sp }}$. The vertical profiles of the column AOD measured on 17 July 2001 by the sun photometer and derived from the in situ measurements are compared in Fig. 2, where the column AOD is defined by Eq. (1) with $z_{2}$ set to infinity. The column AOD from the in situ measurements is equal to that derived from (3) up to the maximum height of the aircraft plus the column AOD measured by the sun photometer at the maximum height of the aircraft. The column AOD measured by the sun photometer should (in theory) decrease monotonically with increasing altitude. However, this is not always the case in practice because of temporal fluctuations and spatial inhomogeneities in the atmosphere during the approximately $15 \mathrm{~min}$ it takes the aircraft to complete a vertical profile. The spatial inhomogeneity estimated 


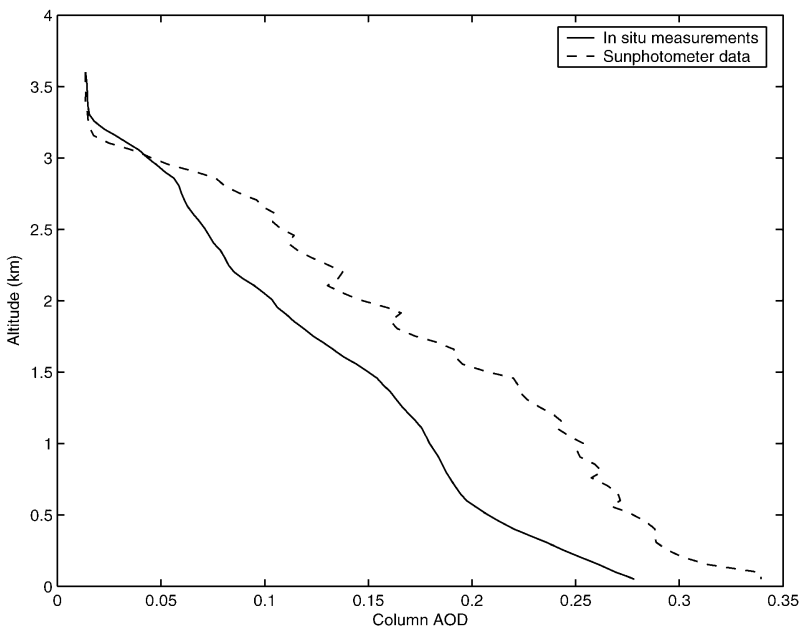

FIG. 2. Comparison of the vertical profile of column aerosol optical depths (AOD) at a wavelength of $550 \mathrm{~nm}$ derived from airborne sun photometer (dashed line) and in situ measurements (solid line) off the East Coast from 1304-1337 UTC on 17 Jul 2001 (UW Flight 1874).

using methods described by Redemann et al. (2003) suggested there was, on average, $27 \% \pm 12 \%$ variability for every $100 \mathrm{~km}$ traveled horizontally in CLAMS. The vertical profiles discussed in this study covered an average horizontal distance of $20 \pm 19 \mathrm{~km}$, which resulted in small potential uncertainties in $\tau_{\text {sun }}$ (Table 3). The column AOD from the in situ measurements decreases monotonically with increasing altitude because it is an integrated quantity with no negative values.

The values of $\tau_{\text {is }}$ and $\tau_{\text {sun }}$ for the vertical profiles of the Convair-580 are listed in Table 3. Figure 3 shows these results. The equation for the relative error-weighted linear regression of $\tau_{\text {is }}$ versus $\tau_{\text {sun }}$ is

$$
\tau_{\text {is }}=(0.85 \pm 0.05) \tau_{\text {sun }}-(0.014 \pm 0.002),
$$

where the linear correlation coefficient is $r=0.992$. Thus, ignoring the small intercept, $\tau_{\text {is }}$ was on average
$15 \% \pm 5 \%$ lower than $\tau_{\text {sun }}$. The root-mean-square (rms) difference between $\tau_{\text {is }}$ and $\tau_{\text {sun }}$ is $0.034 \pm 0.021$. The layer AOD measured on 17 July 2001, had a notably higher $\tau_{\text {is }}$ value than on the other flights. This was primarily due to an increase in total number concentration of particles in the lowest $3 \mathrm{~km}$ of the vertical profile. We attribute this to the parcels near the surface being recirculated through the immediate eastern seaboard region, where they were presumably affected by industrial pollutants (see Fig. 8a). Chemical measurements, discussed below, also indicate higher mass concentrations of sulfate and total carbon on 17 July than on the other flights (Table 4).

\section{b. Chemical composition of the aerosol}

The total mass concentration of the aerosol with diameters $<3 \mu \mathrm{m}$ was measured gravimetrically, and the masses of sulfate, nitrate, and chloride ions were determined using methods described by Gao et al. (2003). The measured gravimetric and ion mass concentrations are listed in Table 4. Sulfate was the only ion consistently present in significant amounts. The masses of crustal elements and cations were not measured.

The total carbon (TC) component of the aerosol mass, defined as the sum of organic carbon (OC) and black carbon (BC), was measured using a thermal evolution method described by Kirchstetter et al. (2003). The results are listed in Table 4 . The analysis did not separate $\mathrm{OC}$ and $\mathrm{BC}$ because the $\mathrm{BC}$ content was below the detection limit of the analysis method. However, BC was estimated to comprise, on average, less than $5 \%$ of the TC measured. Hegg et al. (1997) also reported that $\mathrm{BC}$ was a minor contributor to AOD in TARFOX.

The analysis of particles in CLAMS also provided the mass of oxalic acid $\left(\mathrm{C}_{2} \mathrm{H}_{2} \mathrm{O}_{4}\right)$, which is a dicarboxylic acid that originates from motor exhaust, dust, and soil sources (Kawamura and Kaplan 1987) and in secondary reactions between anthropogenic and natural or-

TABLE 3. Comparison of layer aerosol optical depths at a wavelength of $550 \mathrm{~nm}$ derived from the airborne sun photometer ( $\left.\tau_{\text {sun }}\right)$ and from the in situ measurements $\left(\tau_{\text {is }}\right)$.

\begin{tabular}{|c|c|c|c|c|}
\hline $\begin{array}{c}\text { Date } \\
(2001)\end{array}$ & $\begin{array}{c}\text { UW flight } \\
\text { number }\end{array}$ & $\begin{array}{l}\text { Hypsometric } \\
\text { altitude range } \\
(\mathrm{km}, \mathrm{MSL})\end{array}$ & $\tau_{\text {sun }}$ & $\tau_{\text {is }}$ \\
\hline $14 \mathrm{Jul}$ & 1872 & $0.17-3.17$ & $0.0511 \pm 0.0003$ & $0.037 \pm 0.009$ \\
\hline $14 \mathrm{Jul}$ & 1872 & $0.07-3.90$ & $0.0857 \pm 0.0008$ & $0.066 \pm 0.015$ \\
\hline $16 \mathrm{Jul}$ & 1873 & $0.06-2.94$ & $0.0990 \pm 0.0170$ & $0.055 \pm 0.008$ \\
\hline $17 \mathrm{Jul}$ & 1874 & $0.05-3.60$ & $0.3256 \pm 0.0008$ & $0.265 \pm 0.032$ \\
\hline $23 \mathrm{Jul}$ & 1875 & $0.05-3.09$ & $0.0201 \pm 0.0003$ & $0.011 \pm 0.004$ \\
\hline $23 \mathrm{Jul}$ & 1875 & $1.08-3.22$ & $0.0095 \pm 0.0024$ & $0.002 \pm 0.001$ \\
\hline $26 \mathrm{Jul}$ & 1878 & $0.03-3.17$ & $0.1012 \pm 0.0020$ & $0.086 \pm 0.024$ \\
\hline $26 \mathrm{Jul}$ & 1878 & $0.02-3.11$ & $0.1003 \pm 0.0043$ & $0.093 \pm 0.032$ \\
\hline $30 \mathrm{Jul}$ & 1879 & $0.07-3.17$ & $0.0802 \pm 0.0036$ & $0.016 \pm 0.006$ \\
\hline $30 \mathrm{Jul}$ & 1879 & $0.14-3.22$ & $0.0674 \pm 0.0046$ & $0.010 \pm 0.004$ \\
\hline $31 \mathrm{Jul}$ & 1880 & $0.23-3.26$ & $0.0341 \pm 0.0008$ & $0.013 \pm 0.003$ \\
\hline 2 Aug & 1881 & $0.14-3.22$ & $0.0600 \pm 0.0008$ & $0.047 \pm 0.010$ \\
\hline 2 Aug & 1882 & $0.04-3.19$ & $0.0698 \pm 0.0015$ & $0.053 \pm 0.012$ \\
\hline 2 Aug & 1882 & $0.22-3.21$ & $0.0791 \pm 0.0011$ & $0.042 \pm 0.010$ \\
\hline
\end{tabular}




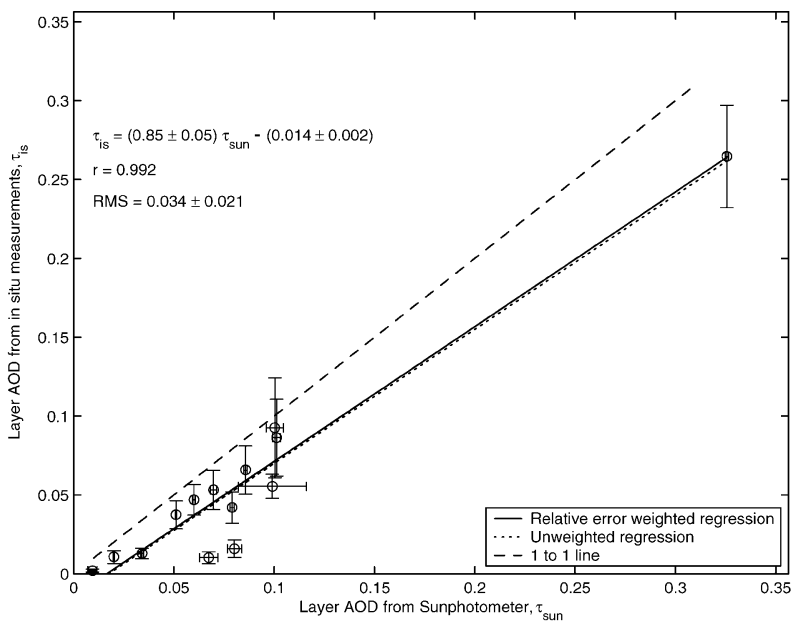

FIG. 3. Comparison of layer AOD at a wavelength of $550 \mathrm{~nm}$ derived from airborne sun photometer $\left(\tau_{\text {sun }}\right)$ and in situ measurements $\left(\tau_{\text {is }}\right)$. The relative error-weighted linear regression to the data points is shown by the solid line; the 1-to-1 perfect correlation is shown by the dashed line. The equation and linear correlation coefficient $(r)$ for the solid line and the rms difference between $\tau_{\text {is }}$ and $\tau_{\text {sun }}$ are shown on the graph.

ganic compounds (e.g., Yokouchi and Ambe 1986; Sempere and Kawamura 1996). The oxalic acid mass concentration is implicitly included in the TC analysis, and is therefore not considered separately in the remainder of this study. As expected, the $\mathrm{C}_{2} \mathrm{H}_{2} \mathrm{O}_{4}$ mass concentration was highly correlated $(p<0.05)$ with the TC values, with $\mathrm{C}_{2} \mathrm{H}_{2} \mathrm{O}_{4}$ comprising, on average, $2 \% \pm 1 \%$ of the TC mass concentration. The average oxalic acid mass concentration from Table 4 is $0.09 \pm 0.04 \mu \mathrm{g}$ $\mathrm{m}^{-3}$, which is lower than the average value of $0.5 \pm$ $0.2 \mu \mathrm{g} \mathrm{m}^{-3}$ measured by Kawamura and Kaplan (1987) in Los Angeles. We attribute the difference to the lower contribution of motor exhaust off the U.S. Atlantic coast than in Los Angeles; the air parcel back trajectories discussed in section $4 \mathrm{~g}$ may also have played a role in the low concentrations of oxalic acid in CLAMS.

\section{c. Overall particle mass scattering efficiency and mass closure}

The overall particle mass scattering efficiency (MSE) of the sampled aerosol was determined by a linear regression (e.g., Bevington and Robinson 1992) of the corrected nephelometer measurements of $\sigma_{\text {spd }}$ to the measured gravimetric mass concentration $\left(m_{g}\right)$. The results of this analysis are shown in Fig. 4, which yield an overall particle MSE of $2.4 \pm 0.2 \mathrm{~m}^{2} \mathrm{~g}^{-1}(r=0.95)$. The corresponding value for TARFOX was $2.8 \pm 0.3$ $\mathrm{m}^{2} \mathrm{~g}^{-1}$ ( $r=0.88$; Hegg et al. 1997). The error bars in Fig. 4 represent the standard deviation of $\sigma_{\text {spd }}$ for the time the filter sample was collected and an uncertainty in $m_{g}$ of $\pm 5 \mu \mathrm{g}$ propagated with the uncertainty in the sample flow volume ( $3 \%$ on average).

The mass closure analysis was performed for the sul- fate and total carbon species (nitrate and chloride species do not improve the degree of closure). The measured mass concentrations of sulfate and total carbon listed in Table 4 account for only portions of their respective molecular forms in the atmosphere. We assumed the sulfate in the atmosphere existed in a oneto-one ratio with ammonium in the form of ammonium bisulfate $\mathrm{NH}_{4} \mathrm{HSO}_{4}$. Therefore, the measured sulfate mass concentrations were multiplied by 1.19 to convert them to mass concentrations of $\mathrm{NH}_{4} \mathrm{HSO}_{4}$. We assumed the total carbon mass concentration was half urban and half nonurban in origin and, using the results of Turpin and Lim (2001), arrived at a molecular conversion factor for carbon of $1.9 \pm 0.3$.

The mass closure results are shown in Fig. 5, where the error bars represent the uncertainty in $m_{g}$, as discussed above, and the propagated error for the mass concentration measurements. The error-weighted linear regression of $m_{g}$ to the sum of the assumed atmospheric forms of sulfate and total carbon $\left(\Sigma m_{s}\right)$ is

$$
m_{g}=(1.06 \pm 0.06) \sum m_{s}+(0.9 \pm 0.5) \text {. }
$$

Hence, on average, $m_{g}$ was $6 \% \pm 6 \%$ greater than $\sum m_{s}$, with about $0.9 \pm 0.5 \mu \mathrm{g} \mathrm{\textrm {m } ^ { - 3 }}$ unaccounted for. This implies that, for particles with diameters $<3 \mu \mathrm{m}$, sulfate and total carbon accounted for an average of $\sim 94 \%$ of the total aerosol mass.

\section{d. Species particle mass scattering efficiencies derived from multiple linear regression}

The mass scattering efficiencies of individual chemical species can be estimated using the multiple linear regression (MLR) method described by White (1990). This method was used by Hegg et al. (1997) on the TARFOX data. The validity of this method was explored by Vasconcelos et al. (2001) in a comparison of theoretical model results with measurements obtained in southern California. They showed that interpretation of the MLR results requires the assumption that the aerosol be externally mixed, which implies that variations in the MSE of the various species are independent of the mass concentrations of other species.

Based on the mass closure analysis discussed above, we perform an MLR of $\sigma_{\mathrm{spd}}$ to the mass concentrations of sulfate and total carbon using

$$
\sigma_{\text {spd }}=\alpha_{\text {sulfate }}\left(m_{\text {sulfate }}\right)+\alpha_{\text {total carbon }}\left(m_{\text {total carbon }}\right),
$$

where $\sigma_{\text {spd }}$ is the dried aerosol light scattering coefficient (in units of $\mathrm{Mm}^{-1}$ ), $\alpha_{x}$ the mass scattering efficiency of species $x\left(\mathrm{~m}^{2} \mathrm{~g}^{-1}\right)$, and $m_{x}$ the mass concentration of species $x\left(\mu \mathrm{g} \mathrm{m}^{-3}\right)$. All mass scattering efficiencies reported hereafter imply units of $\mathrm{m}^{2}\left(\mathrm{~g} \mathrm{SO}_{4}^{=}\right)^{-1}$ and $\mathrm{m}^{2}$ (g C $)^{-1}$ for $\alpha_{\text {sulfate }}$ and $\alpha_{\text {total carbon }}$, respectively. We obtained the following from the MLR analysis of the CLAMS data:

$\sigma_{\text {spd }}=(6.0 \pm 1.0) m_{\text {sulfate }}+(2.6 \pm 0.9) m_{\text {total carbon }}$, 
TABLE 4. In situ airborne measurements of meteorological state parameters, dry aerosol properties, and aerosol species mass concentrations for particles with diameters $<3 \mu \mathrm{m}$.

\begin{tabular}{|c|c|c|c|c|c|c|c|c|c|c|c|}
\hline $\begin{array}{l}\text { Date } \\
(2001)\end{array}$ & $\begin{array}{c}\text { UW } \\
\text { flight } \\
\text { number }\end{array}$ & $\begin{array}{l}\text { Latitude } \\
\left({ }^{\circ} \mathrm{N}\right)\end{array}$ & $\begin{array}{l}\text { Longitude } \\
\left({ }^{\circ} \mathrm{W}\right)\end{array}$ & $\begin{array}{c}\text { Mean } \\
\text { hypsometric } \\
\text { altitude } \\
\text { (km, MSL) }\end{array}$ & $\begin{array}{c}\text { Mean } \\
\text { ambient } \\
\text { pressure } \\
(\mathrm{hPa})\end{array}$ & $\begin{array}{c}\text { Mean } \\
\text { ambient } \\
\text { temperature } \\
(\mathrm{K})\end{array}$ & $\begin{array}{l}\text { Mean } \\
\text { ambient } \\
\text { relative } \\
\text { humidity } \\
\quad(\%)\end{array}$ & $\begin{array}{c}\text { Total particle } \\
\text { number } \\
\text { concentra- } \\
\text { tion } \\
\left(\mathrm{cm}^{-3}\right)\end{array}$ & $\begin{array}{l}d_{g, \mathrm{acc}}^{\mathrm{a}, \mathrm{b}} \\
(\mu \mathrm{m})\end{array}$ & $\begin{array}{c}d_{\text {smd,acc }}^{\mathrm{a}, \mathrm{b}} \\
(\mu \mathrm{m})\end{array}$ & $\sigma_{g, \mathrm{acc}}^{\mathrm{a}, \mathrm{b}}$ \\
\hline $10 \mathrm{Jul}$ & 1870 & 36.883 & 75.617 & 3.24 & 693 & 279 & 69 & 360 & 0.20 & 0.26 & 1.44 \\
\hline $10 \mathrm{Jul}$ & 1870 & 36.908 & 75.718 & 1.29 & 870 & 292 & 70 & 1962 & 0.18 & 0.23 & 1.41 \\
\hline $12 \mathrm{Jul}$ & 1871 & 37.002 & 75.477 & 1.91 & 811 & 283 & 72 & 866 & 0.20 & 0.25 & 1.39 \\
\hline $12 \mathrm{Jul}$ & 1871 & 37.052 & 75.395 & 0.64 & 941 & 291 & 55 & 893 & 0.16 & 0.20 & 1.32 \\
\hline $16 \mathrm{Jul}$ & 1873 & 36.566 & 74.803 & 0.20 & 995 & 296 & 59 & 1360 & 0.18 & 0.22 & 1.36 \\
\hline $17 \mathrm{Jul}$ & 1874 & 36.915 & 75.508 & 2.93 & 725 & 279 & 65 & 871 & 0.22 & 0.30 & 1.49 \\
\hline $17 \mathrm{Jul}$ & 1874 & 36.902 & 75.303 & 2.03 & 806 & 285 & 65 & 1345 & 0.20 & 0.25 & 1.40 \\
\hline $17 \mathrm{Jul}$ & 1874 & 36.884 & 75.382 & 1.10 & 899 & 293 & 49 & 1300 & 0.19 & 0.24 & 1.38 \\
\hline $17 \mathrm{Jul}$ & 1874 & 36.894 & 75.554 & 0.09 & 1008 & 298 & 72 & 1706 & 0.21 & 0.26 & 1.41 \\
\hline $23 \mathrm{Jul}$ & 1875 & 37.896 & 74.137 & 0.55 & 957 & 295 & 80 & 104 & 0.18 & 0.24 & 1.40 \\
\hline $26 \mathrm{Jul}$ & 1878 & 37.144 & 75.528 & 0.17 & 994 & 298 & 83 & 505 & 0.19 & 0.28 & 1.49 \\
\hline $26 \mathrm{Jul}$ & 1878 & 36.711 & 74.851 & 0.64 & 943 & 296 & 77 & 450 & 0.19 & 0.28 & 1.48 \\
\hline $30 \mathrm{Jul}$ & 1879 & 36.905 & 75.490 & 0.15 & 1000 & 294 & 77 & 123 & 0.17 & 0.26 & 1.38 \\
\hline $31 \mathrm{Jul}$ & 1880 & 38.088 & 72.641 & 0.78 & 939 & 290 & 73 & 161 & 0.17 & 0.22 & 1.34 \\
\hline 2 Aug & 1881 & 36.997 & 75.661 & 0.12 & 1012 & 296 & 70 & 459 & 0.17 & 0.21 & 1.34 \\
\hline 2 Aug & 1881 & 37.251 & 74.879 & 0.93 & 922 & 291 & 63 & 805 & 0.18 & 0.23 & 1.37 \\
\hline 2 Aug & 1881 & 37.020 & 75.011 & 0.53 & 966 & 294 & 65 & 412 & 0.18 & 0.22 & 1.35 \\
\hline
\end{tabular}

${ }^{a}$ Determined from measurements made by a heated PCASP-100x particle size distribution probe (15 channels from diameters $\left.0.11-4.5 \mu \mathrm{m}\right)$ during the period of filter sample collection.

${ }^{\mathrm{b}}$ Assuming a lognormal dry particle size distribution, $d_{g}$ is the geometric mean diameter, $d_{\text {smd }}$ the surface median diameter, and $\sigma_{g}$ the geometric standard deviation. The subscripts "acc" and "coa" indicate the accumulation-mode (diameters $0.11-1.0 \mu m)$ and the coarsemode (diameters $1.0-4.5 \mu \mathrm{m})$, respectively.

${ }^{c}$ At standard temperature $(273.15 \mathrm{~K})$ and pressure $(1013.25 \mathrm{hPa})$ and at a wavelength of $550 \mathrm{~nm}$.

with $r=0.98$ and $\alpha_{x}$ derived from values of $\sigma_{\text {spd }}$ and $m_{x}$ listed in Table 4 for all flights (except the 10 July sample collected at $3.24-\mathrm{km}$ altitude, since $m_{\text {sulfate }}$ was not measured on this flight). The relationship (9) assumes that only sulfate and total carbon contributed to $\sigma_{\text {spd }}$. The MLR analysis showed that other species contributed $\sim 10 \%$ to $\sigma_{\mathrm{spd}}$ and were therefore ignored.

Values of $\alpha_{\text {sulfate }}$ for a dry aerosol at a wavelength of $550 \mathrm{~nm}$ fall in the range $\sim 3-7 \mathrm{~m}^{2} \mathrm{~g}^{-1}$ (Charlson et al. 1999). Boucher and Anderson (1995) derived an average value of $3.4 \pm 0.8 \mathrm{~m}^{2} \mathrm{~g}^{-1}$ for $\alpha_{\text {sulfate }}$ by varying parameters such as the particle size distribution and chemical form of atmospheric sulfate in Mie scattering model calculations. Values of $\alpha_{\text {sulfate }}$ ranged from 3.1$5.1 \mathrm{~m}^{2} \mathrm{~g}^{-1}$ in studies reported between 1993-2000 (Haywood and Boucher 2000). Using the MLR method on data collected off the East Coast in the TARFOX field study, Hegg et al. (1997) derived a value of $3.2 \pm 1.3$ $\mathrm{m}^{2} \mathrm{~g}^{-1}$ for $\alpha_{\text {sulfate }}$. White (1990) obtained a value for $\alpha_{\text {sulfate }}$ of $7.1 \pm 0.5 \mathrm{~m}^{2} \mathrm{~g}^{-1}$ at a wavelength of $525 \mathrm{~nm}$, which would be slightly lower for a wavelength of 550 nm.

Previous values of $\alpha_{\text {total carbon }}$ for a dry aerosol, derived from theoretical and measured particle size distributions inputted into Mie scattering models, range from $\sim 3-5$ $\mathrm{m}^{2} \mathrm{~g}^{-1}$ (e.g., Shekar Reddy and Venkataraman 2000; Penner et al. 1998; Liousse et al. 1996). Zhang et al. (1994) derived an average value of $3.9 \pm 1.5 \mathrm{~m}^{2} \mathrm{~g}^{-1}$ at a wavelength of $525 \mathrm{~nm}$ for data collected in the southwestern United States. Hegg et al. (1997) derived values of $\alpha_{\text {total carbon }}$ of $6.8 \mathrm{~m}^{2} \mathrm{~g}^{-1}$ using the MLR method on data collected off the East Coast in TARFOX. White (1990) used the MLR method to derive a value for $\alpha_{\text {organic carbon }}$ of $4.7 \pm 0.5 \mathrm{~m}^{2} \mathrm{~g}^{-1}$ at a wavelength of 525 $\mathrm{nm}$ from a relatively large (47 data points) dataset collected mainly in the western United States. If we assume that in White's samples the mass of black carbon was $10 \%$ of the mass of organic carbon, the value for $\alpha_{\text {total carbon }}$ would have been $4.3 \pm 0.5 \mathrm{~m}^{2} \mathrm{~g}^{-1}$. The values for $\alpha_{\text {total carbon }}$ given by Zhang et al., and derived from White's data, will decrease slightly when interpolated to a wavelength of $550 \mathrm{~nm}$.

The values for $\alpha_{\text {sulfate }}$ and $\alpha_{\text {total carbon }}$ at a wavelength of $550 \mathrm{~nm}$ derived from the present study $(6.0 \pm 1.0$ and $2.6 \pm 0.9 \mathrm{~m}^{2} \mathrm{~g}^{-1}$, respectively) fall within a standard deviation of the range of values of earlier work. Our derived mean value for $\alpha_{\text {total carbon }}$ is generally lower than previously measured. This may be because the aerosol in CLAMS was internally mixed to the point where $m_{\text {sulfate }}$ and $m_{\text {total carbon }}$ were interdependent (Vasconcelos et al. 2001).

The results of MLR analyses can be affected by significant variations in the dry particle size distributions (Zhang et al. 1994). In general, the particle size distributions in this study were bimodal with a peak in the accumulation mode at diameter $<1 \mu \mathrm{m}$ and a second less distinct peak in the coarse mode at diameters between 1 and $4.5 \mu \mathrm{m}$. Total particle number concentrations averaged $800 \pm 600 \mathrm{~cm}^{-3}$. The mean values of the geometric mean diameter, surface median diameter 
TABLE 4. (Extended)

\begin{tabular}{|c|c|c|c|c|c|c|}
\hline $\begin{array}{l}d_{g, \mathrm{coa}}^{\mathrm{a}, \mathrm{b}} \\
(\mu \mathrm{m})\end{array}$ & $\begin{array}{c}d_{\mathrm{smd}, \mathrm{a} \text {, } \mathrm{aa}} \\
(\mu \mathrm{m})\end{array}$ & $\sigma_{g, \mathrm{coa}}^{\mathrm{a}, \mathrm{b}}$ & $\begin{array}{l}\text { Dry light } \\
\text { scattering } \\
\text { coefficient }^{\mathrm{c}} \\
\left(\mathrm{Mm}^{-1}\right)\end{array}$ & $\begin{array}{l}\text { Dry light } \\
\text { absorption } \\
\text { coefficient }^{\mathrm{c}} \\
\left(\mathrm{Mm}^{-1}\right)\end{array}$ & $\begin{array}{l}\text { Derived } \\
\text { dry single } \\
\text { scattering } \\
\text { albedo }^{c}\end{array}$ & $\begin{array}{c}\text { Gravimetric mass } \\
\text { concentration of } \\
\text { particles with } \\
\text { diameters }<3 \\
\mu \mathrm{m}\left(\mu \mathrm{g} \mathrm{m}^{-3}\right)\end{array}$ \\
\hline 1.87 & 2.66 & 1.49 & $18 \pm 4$ & $2.7 \pm 0.8$ & 0.87 & no data \\
\hline 1.77 & 2.63 & 1.55 & $75 \pm 7$ & $6.7 \pm 0.9$ & 0.92 & $35.4 \pm 2.8$ \\
\hline 2.04 & 2.94 & 1.49 & $36 \pm 7$ & $2.8 \pm 1.0$ & 0.93 & $13.3 \pm 1.8$ \\
\hline 1.85 & 2.80 & 1.54 & $15 \pm 3$ & $2.3 \pm 0.8$ & 0.87 & $7.0 \pm 1.0$ \\
\hline 1.73 & 2.50 & 1.51 & $40 \pm 5$ & $2.8 \pm 0.9$ & 0.94 & $19.2 \pm 1.4$ \\
\hline 1.48 & 1.97 & 1.46 & $87 \pm 16$ & $3.0 \pm 1.7$ & 0.97 & $34.4 \pm 2.8$ \\
\hline 1.68 & 2.63 & 1.58 & $59 \pm 8$ & $3.6 \pm 2.4$ & 0.94 & $22.1 \pm 2.7$ \\
\hline 1.62 & 2.12 & 1.46 & $52 \pm 5$ & $3.4 \pm 0.7$ & 0.94 & $20.3 \pm 2.4$ \\
\hline 1.81 & 2.69 & 1.53 & $104 \pm 22$ & $4.3 \pm 0.5$ & 0.96 & $38.7 \pm 2.2$ \\
\hline 1.59 & 2.21 & 1.50 & $7 \pm 3$ & $1.6 \pm 0.6$ & 0.80 & $2.9 \pm 0.8$ \\
\hline 1.65 & 2.38 & 4.48 & $50 \pm 8$ & $2.4 \pm 0.3$ & 0.95 & $12.2 \pm 2.3$ \\
\hline 1.68 & 2.46 & 2.64 & $37 \pm 5$ & $2.3 \pm 0.5$ & 0.94 & $9.0 \pm 1.0$ \\
\hline 1.61 & 2.13 & 1.46 & $14 \pm 1$ & $1.9 \pm 0.7$ & 0.88 & $5.7 \pm 0.9$ \\
\hline 1.62 & 2.27 & 1.51 & $8 \pm 3$ & $1.7 \pm 1.0$ & 0.81 & $3.6 \pm 0.5$ \\
\hline 1.64 & 2.33 & 1.52 & $15 \pm 2$ & $2.9 \pm 0.7$ & 0.84 & $8.0 \pm 1.3$ \\
\hline 1.82 & 2.68 & 1.52 & $25 \pm 7$ & $2.1 \pm 0.5$ & 0.92 & $11.3 \pm 1.5$ \\
\hline 1.77 & 2.62 & 1.52 & $19 \pm 3$ & $2.5 \pm 1.9$ & 0.88 & $14.0 \pm 1.9$ \\
\hline
\end{tabular}

and geometric standard deviation of the data listed in Table 4 for the accumulation mode are $d_{g \text {, acc }}=0.19 \pm$ $0.02 \mu \mathrm{m}, d_{\text {smd,acc }}=0.24 \pm 0.03 \mu \mathrm{m}$ and $\sigma_{g \text {,acc }}=1.40$ \pm 0.05 , respectively. The corresponding mean values for the coarse mode are $d_{g \text {, coa }}=1.7 \pm 0.1 \mu \mathrm{m}, d_{\text {smd,coa }}$ $=2.5 \pm 0.3 \mu \mathrm{m}$, and $\sigma_{g, \text { coa }}=1.8 \pm 0.8$. Hence, the accumulation mode (which accounts for the majority of the scattering) was stable to within $\sim 10 \%$, which makes it unlikely that variations in the dry particle size distribution affected the MLR results reported here.

\section{e. Chemical apportionment of the aerosol optical depth}

The MLR results presented in the previous section can be applied to the individual vertical profiles that, together with the simultaneous measurements of $m_{\text {sulfate }}$ and $m_{\text {total carbon }}$ from the filter analysis (Table 4), can be used to estimate the contributions of sulfate and total carbon to the AOD. The values of $m_{x}$ (the mass concentration of species $x$ ) were determined by averaging the individual $m_{x}$ values for each UW flight to arrive at an average value (and standard deviation) for the vertical profile. Then, using the values of $\alpha_{\text {sulfate }}$ and $\alpha_{\text {total carbon }}$ determined in section 4.4, the contributions of sulfate and total carbon to the AOD were determined. For example, the fraction of light scattering contributed by sulfate, $\sigma_{\text {sp-sulfate }}$, is given by

$$
\sigma_{\text {sp-sulfate }}=\frac{\alpha_{\text {sulfate }} m_{\text {sulfate }}}{\alpha_{\text {sulfate }} m_{\text {sulfate }}+\alpha_{\text {total carbon }} m_{\text {total carbon }}} .
$$

TABLE 4. (Extended).

\begin{tabular}{|c|c|c|c|c|c|}
\hline $\begin{array}{c}\text { Date } \\
(2001)\end{array}$ & $\begin{array}{l}\text { Total carbon } \\
\text { concentration } \\
\left(\mu \mathrm{g} \mathrm{m}^{-3}\right)\end{array}$ & $\begin{array}{c}\text { Sulfate } \\
\text { concentration } \\
\left(\mu \mathrm{g} \mathrm{m}^{-3}\right)\end{array}$ & $\begin{array}{l}\text { Oxalic acid } \\
\text { concentration } \\
\left(\mu \mathrm{g} \mathrm{m}^{-3}\right)\end{array}$ & $\begin{array}{c}\text { Nitrate } \\
\text { concentration } \\
\left(\mu \mathrm{g} \mathrm{m}^{-3}\right)\end{array}$ & $\begin{array}{c}\text { Chloride } \\
\text { concentration } \\
\left(\mu \mathrm{g} \mathrm{m}^{-3}\right)\end{array}$ \\
\hline $10 \mathrm{Jul}$ & $6.0 \pm 1.8$ & no data & no data & no data & no data \\
\hline $10 \mathrm{Jul}$ & $7.8 \pm 2.3$ & $7.00 \pm 0.06$ & $0.176 \pm 0.006$ & $0.157 \pm 0.016$ & $0.03 \pm 0.05$ \\
\hline $12 \mathrm{Jul}$ & $5.5 \pm 1.6$ & $2.49 \pm 0.04$ & $0.074 \pm 0.004$ & $0.054 \pm 0.011$ & $0 \pm 0.03$ \\
\hline $12 \mathrm{Jul}$ & $2.5 \pm 0.7$ & $2.07 \pm 0.02$ & $0.031 \pm 0.002$ & $0.047 \pm 0.006$ & $0 \pm 0.02$ \\
\hline $16 \mathrm{Jul}$ & $3.2 \pm 1.0$ & $6.61 \pm 0.03$ & $0.087 \pm 0.003$ & $0.044 \pm 0.008$ & $0.03 \pm 0.02$ \\
\hline $17 \mathrm{Jul}$ & $8.7 \pm 2.6$ & $11.72 \pm 0.06$ & $0.063 \pm 0.006$ & $0.019 \pm 0.016$ & $0 \pm 0.00$ \\
\hline $17 \mathrm{Jul}$ & $10.9 \pm 3.3$ & $6.62 \pm 0.06$ & $0.114 \pm 0.006$ & $0.708 \pm 0.016$ & no data \\
\hline $17 \mathrm{Jul}$ & $7.7 \pm 2.3$ & $6.90 \pm 0.05$ & $0.070 \pm 0.005$ & $0.027 \pm 0.014$ & $0.03 \pm 0.04$ \\
\hline $17 \mathrm{Jul}$ & $9.0 \pm 2.7$ & $12.28 \pm 0.05$ & $0.160 \pm 0.004$ & $0.084 \pm 0.012$ & $0.02 \pm 0.04$ \\
\hline $23 \mathrm{Jul}$ & $0.6 \pm 0.2$ & $0.85 \pm 0.02$ & $0.028 \pm 0.002$ & $0.151 \pm 0.005$ & $0.09 \pm 0.01$ \\
\hline $26 \mathrm{Jul}$ & $4.7 \pm 1.4$ & $3.39 \pm 0.05$ & $0.078 \pm 0.005$ & $0.428 \pm 0.013$ & $0.10 \pm 0.04$ \\
\hline $26 \mathrm{Jul}$ & $2.6 \pm 0.8$ & $2.79 \pm 0.02$ & $0.087 \pm 0.002$ & $0.206 \pm 0.006$ & $0 \pm 0.02$ \\
\hline $30 \mathrm{Jul}$ & $1.0 \pm 0.3$ & $0.57 \pm 0.02$ & $0.029 \pm 0.002$ & $0.294 \pm 0.006$ & $1.21 \pm 0.02$ \\
\hline $31 \mathrm{Jul}$ & $1.0 \pm 0.3$ & $0.65 \pm 0.01$ & $0.045 \pm 0.001$ & $0.146 \pm 0.003$ & $0.39 \pm 0.01$ \\
\hline 2 Aug & $3.1 \pm 0.9$ & $1.21 \pm 0.03$ & $0.102 \pm 0.003$ & $0.105 \pm 0.008$ & $0 \pm 0.02$ \\
\hline 2 Aug & $5.2 \pm 1.6$ & $2.13 \pm 0.03$ & $0.149 \pm 0.003$ & $0.047 \pm 0.009$ & $0 \pm 0.03$ \\
\hline 2 Aug & $5.3 \pm 1.6$ & $1.67 \pm 0.04$ & $0.104 \pm 0.004$ & $0.113 \pm 0.012$ & $0 \pm 0.03$ \\
\hline
\end{tabular}




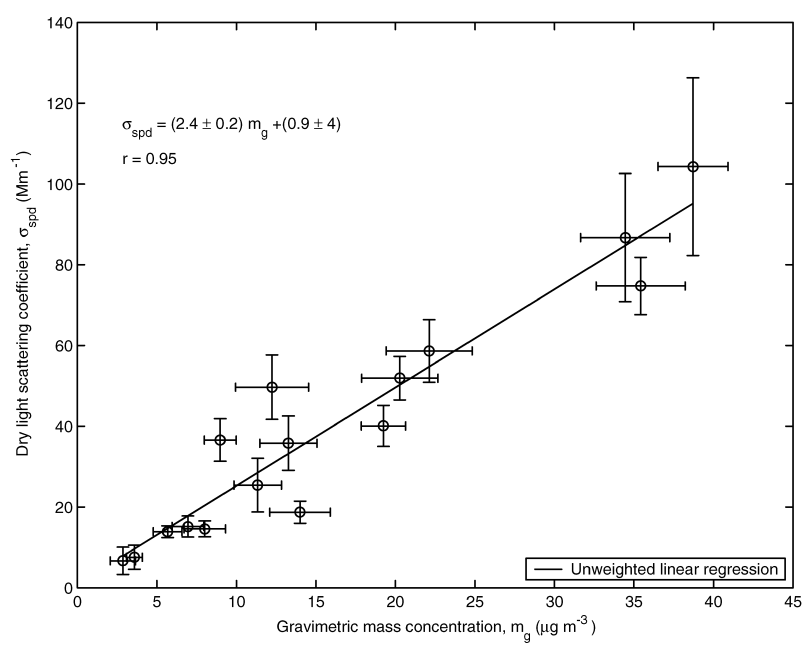

FIG. 4. Linear regression of the dry light scattering coefficient $\sigma_{\mathrm{spd}}$ at $550 \mathrm{~nm}$ to the gravimetric mass concentration $m_{g}$. The error bars indicate the standard deviation of $\sigma_{\text {spd }}$ over the time interval of the filter sample used to determine $m_{g}$, and the uncertainty of $m_{g}$ as listed in Table 4. The particle mass scattering efficiency is the slope of the regression line shown here.

The hygroscopic growth functions [Eq.(4)] were used to determine the difference between the AOD of a dry layer and a hydrated layer, which provides the contribution of condensed water to the layer AOD. The fraction of the layer AOD due to light absorption was determined from the PSAP measurements.

The contributions of sulfate, total carbon, condensed water and absorption to the layer AODs are listed in Table 5 , and the percentage contributions of species to the total layer AOD are given in Table 6. Figure 6 shows

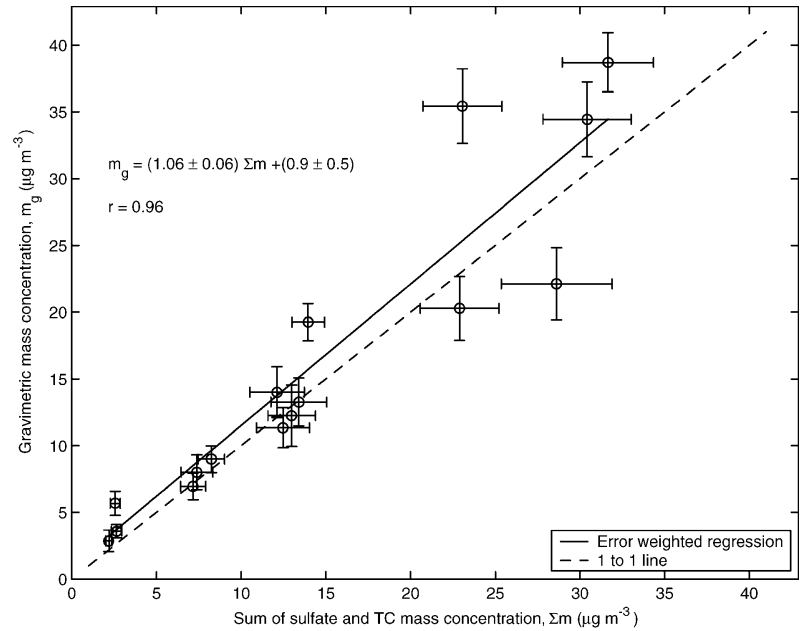

FIG. 5. Error-weighted linear regression of the gravimetric mass concentration $m_{g}$ to the sum of the sulfate and total carbon species mass concentrations $\Sigma m$. The equation for the error-weighted regression line (solid line) is given on the graph. The dashed line is the 1-to-1 perfect correlation line. Error bars are the uncertainty in $m_{g}$ and the propagation of the uncertainty in $\Sigma m$, all of which are listed in Table 4.

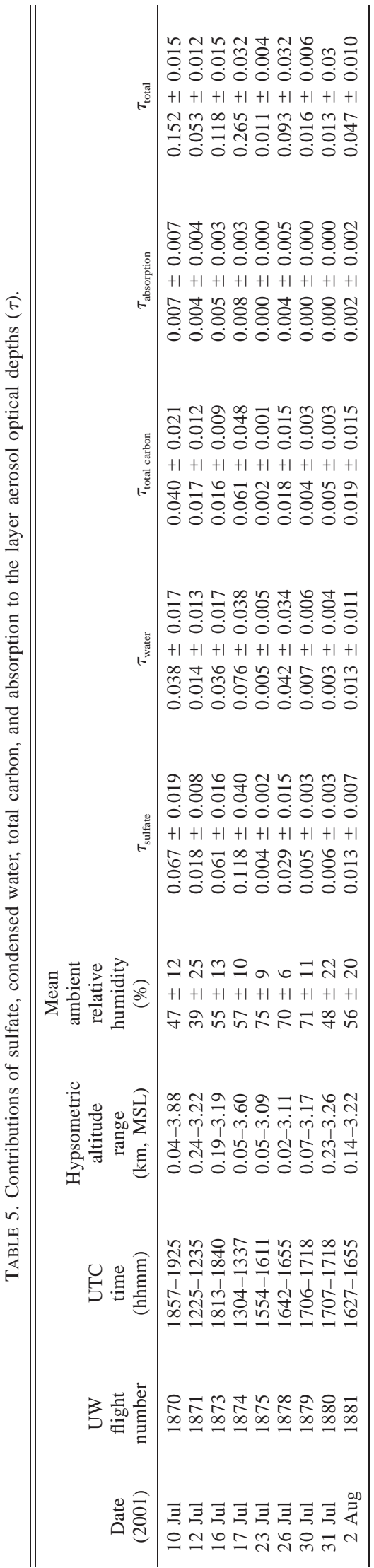




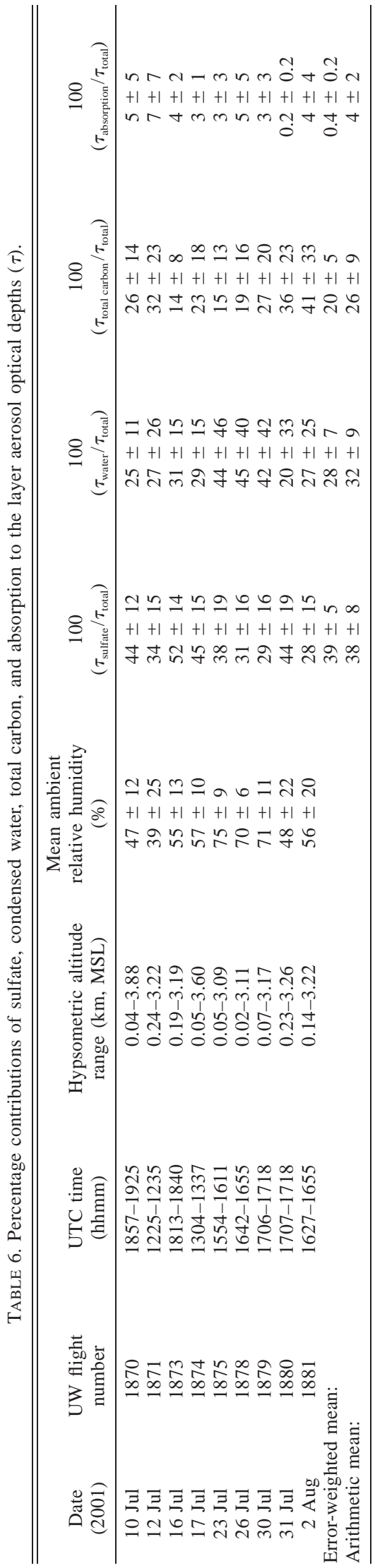

these results in graphical form. The mean values of the contributions of sulfate, total carbon and condensed water to the layer AODs in CLAMS were similar, averaging $38 \% \pm 8 \%, 26 \% \pm 9 \%$, and $32 \% \pm 9 \%$, respectively. Since the errors associated with the individual contributions vary, we calculated error-weighted averages; this yielded sulfate, total carbon, and condensed water contributions to the layer AODs of $39 \% \pm 5 \%, 20 \% \pm$ $5 \%$, and $28 \% \pm 7 \%$, respectively. Clearly, sulfate was the largest contributor to the layer AOD in CLAMS. The contributions of absorption to the layer AODs were small $(0.4 \%-4 \%)$ in all cases.

\section{f. Single scattering albedo}

The aerosol single scattering albedo $\left(\omega_{0}\right)$ is an important input to direct radiative forcing calculations. A sample profile of $\omega_{0}$ is shown in Fig. 1. This particular case shows a much deeper polluted layer than was generally encountered in CLAMS (we define polluted layers as regions where $\sigma_{\mathrm{sp}}>30 \mathrm{Mm}^{-1}$ in the vertical profiles listed in Table 2). Figure 7 shows the distribution of $\omega_{0}$ values [calculated from Eq. (5)] in the polluted layer for all of the vertical profiles. The mean value of $\omega_{0}$, based on 150 data points, is $0.96 \pm 0.03$.

Ground-based retrievals of $\omega_{0}$ were also obtained by the Aerosol Robotic Network (AERONET) sun photometers (e.g., Dubovik et al. 2000) during the CLAMS field campaign from a site known as the Clouds and the Earth's Radiant Energy System (CERES) Ocean Validation Experiment (COVE; $\left.36.9^{\circ} \mathrm{N}, 75.7^{\circ} \mathrm{W}\right)$. The vertical profiles in Table 2 were often spatially located close to COVE. The mean value of $\omega_{0}$ at $550 \mathrm{~nm}$ from AERONET retrieval data (processed to remove clouds and manually quality assured) is $0.94 \pm 0.03$. Therefore, the mean value of $\omega_{0}$ retrieved from AERONET agrees with mean value of $\omega_{0}$ derived from our in situ airborne measurements $(0.96 \pm 0.03)$ to within one standard deviation.

On 17 July 2001, measurements were made from the UW aircraft and the COVE site that were both temporally (the aircraft vertical profile was from 1304-1337 UTC and the AERONET retrieval was at 1310 UTC) and spatially (the aircraft was $\sim 2.5 \mathrm{~km}$ from COVE) collocated. The mean value of $\omega_{0}$ calculated from the airborne in situ measurements made in polluted layers during this vertical profile was $0.97 \pm 0.02$; the corresponding column-averaged value of $\omega_{0}$ for accumulation mode particles retrieved from the AERONET data was $0.90 \pm 0.03$. Particle losses in the sampling system for the in situ instruments could have contributed to an underestimate of the absorbing component of the aerosol. Spatial variability may have played a role as well. Redemann et al. (2005) show that during CLAMS, the horizontal variability of AOD at midvisible wavelengths varied from $1 \%$ to $26 \%$ on scales less than $20 \mathrm{~km}$. The values of $\omega_{0}$ derived from the AERONET measurements are also subject to uncertainties at low solar zenith an- 

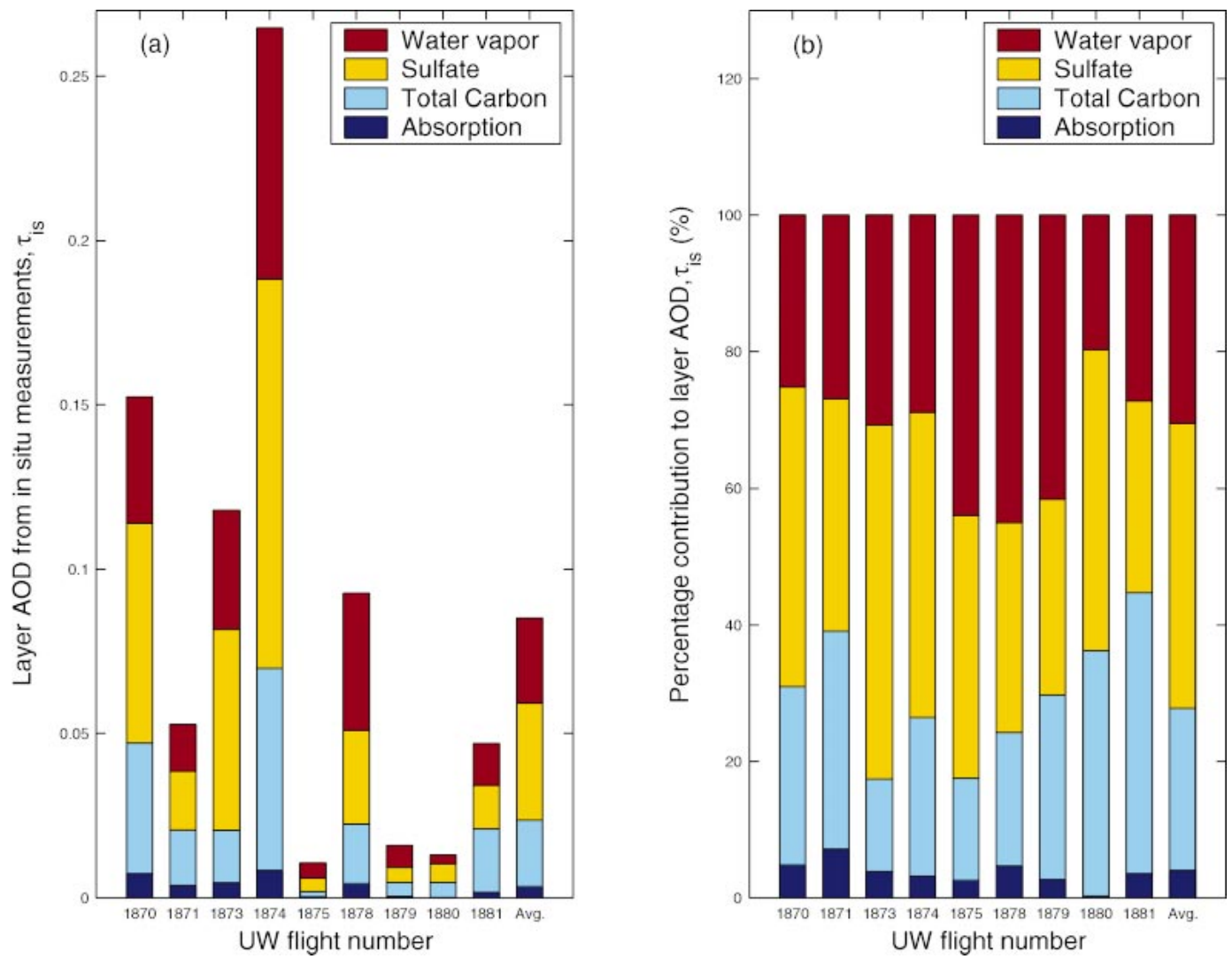

FIG. 6. Contributions to the layer AOD measured by the in situ instruments $\left(\tau_{\text {is }}\right)$ in (a) units of layer AOD and (b) percentage contribution to layer AOD. The average contributions for the nine flights are shown in the last column in both (a) and (b).

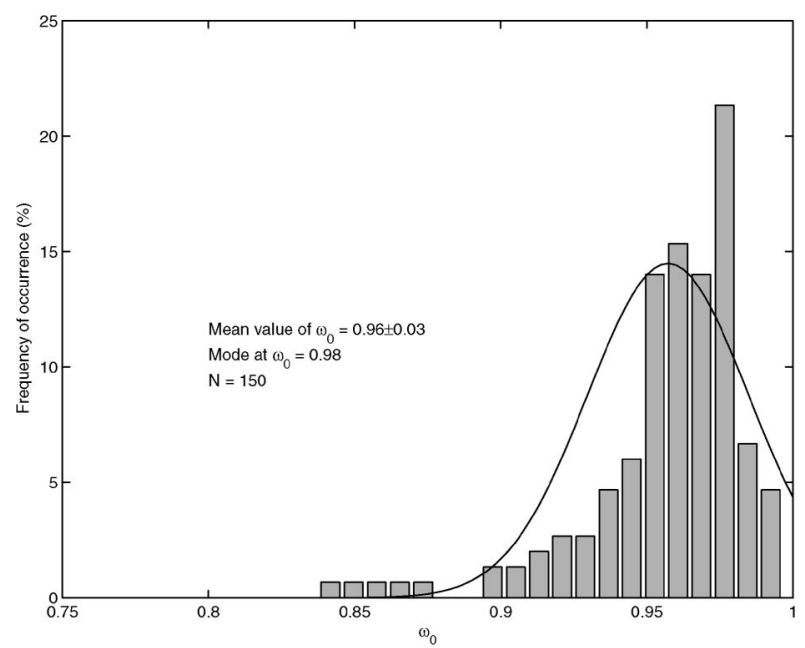

FIG. 7. Frequency distributions of the aerosol single scattering albedo $\left(\omega_{0}\right)$ at a wavelength of $550 \mathrm{~nm}$ for the polluted layers of the vertical profiles listed in Table 2. Polluted layers were defined as regions in vertical profiles where the light scattering coefficient corrected to the ambient $\mathrm{RH}$ was greater than $30 \mathrm{Mm}^{-1}$. The mean value of $\omega_{0}$, the standard deviation, the number of data points $(N)$, and the value of $\omega_{0}$ with the maximum frequency of occurrence, are shown on the figure. The Gaussian curve defined by the mean and standard deviation is overlaid. gles $\left(54^{\circ}\right.$ at the time of the almucanter scan on 17 July) and for low AOD at midvisible wavelengths (Dubovik et al. 2000).

\section{g. Comparison with TARFOX results}

Since the measurements reported here were obtained in the same general location and time of year, and using the same techniques, as the TARFOX measurements reported by Hegg et al. (1997), it is of interest to compare them. The values of $\alpha_{\text {sulfate }}$ and $\alpha_{\text {total carbon }}$ derived from the TARFOX measurements were $3.2 \pm 1.3 \mathrm{~m}^{2}$ $\left(\mathrm{g} \mathrm{SO}_{4}^{=}\right)^{-1}$ and $6.8 \pm 1.1 \mathrm{~m}^{2}\left(\mathrm{~g} \mathrm{C}^{-1}\right.$, compared to 6.0 $\pm 1.0 \mathrm{~m}^{2}\left(\mathrm{~g} \mathrm{SO}_{4}^{=}\right)^{-1}$ and $2.6 \pm 0.9 \mathrm{~m}^{2}(\mathrm{~g} \mathrm{C})^{-1}$ derived here. The chemical apportionment reported here gives a higher mean sulfate contribution (38\%) to the layer AOD at $550 \mathrm{~nm}$ than that obtained in TARFOX (19\%). In the present study, the mean value of $\omega_{0}$ at the ambient RH is $0.96 \pm 0.03$ (Fig. 7), and the mean value of $\omega_{0}$ at $30 \% \mathrm{RH}$ is $0.94 \pm 0.04$. For TARFOX, the mean value of $\omega_{0}$ at ambient $\mathrm{RH}$ was $\sim 0.94$, and the mean value of $\omega_{0}$ at $30 \% \mathrm{RH}$ was $0.90 \pm 0.06$.

The mean values of geometric mean diameter $\left(d_{g}\right)$, the surface median diameter $\left(d_{\mathrm{smd}}\right)$ and geometric standard deviation $\left(\sigma_{g}\right)$ for particle diameters $<1 \mu \mathrm{m}$ in this 
study (Table 4) are $0.19 \pm 0.02 \mu \mathrm{m}, 0.24 \pm 0.03 \mu \mathrm{m}$, and $1.40 \pm 0.05$, respectively. The corresponding values for TARFOX were very similar: $d_{g \text {, acc }}=0.19 \pm 0.02$ $\mu \mathrm{m}, d_{\text {smd,acc }}=0.24 \pm 0.03 \mu \mathrm{m}$, and $\sigma_{g, \text { acc }}=1.40 \pm$ 0.04 . However, the mean value of the total particle number concentration in this study was $800 \mathrm{~cm}^{-3}$ while for TARFOX it was $1600 \mathrm{~cm}^{-3}$. The higher particle number concentrations clearly contributed to the higher average layer AOD in TARFOX.

Although the characteristics of the accumulation mode were similar in TARFOX and CLAMS, the sulfate contribution to the visible layer AOD was quite different. This implies that the differences in the values of $\alpha_{\text {sulfate }}$ and $\alpha_{\text {total carbon }}$ in TARFOX and CLAMS are due to differences in the size-resolved species concentrations of sulfate and total carbon. If this is the case, the sulfate (total carbon) concentrations in the accumulation mode in CLAMS are greater (less) than those in TARFOX. Unfortunately, since size-resolved species concentrations are not available for either TARFOX or CLAMS, we are unable to test this hypothesis.

Synoptic conditions could also account in part for the differences between the results presented here and those obtained in TARFOX. In the last two columns of Table 2 we summarize results from 72-h parcel back-trajectory analyses for the CLAMS case studies discussed here. The trajectories show that the air sampled off the East Coast in CLAMS generally had passed earlier over Canada, the Atlantic Ocean, or the Gulf of Mexico. For example, for UW flights 1870-1873, the air sampled above $\sim 200 \mathrm{~m}$ passed over Canada. For UW flights 1875-1882, the air sampled at all altitudes passed over either the Nova Scotia region or the Gulf of Mexico. For UW flight 1874 , air up to $\sim 1.5 \mathrm{~km}$ passed over the immediate East Coast, while above $1.5 \mathrm{~km}$ it passed over the Great Lakes. Air sampled in UW flight 1874 was primarily ascending, but the air sampled in the other flights was generally subsiding. Figure 8 shows the results of 72-h back-trajectory analysis for UW flight 1874. In TARFOX the highest layer AODs occurred with airflows from the west and southwest, while the lowest layer AODs generally occurred with airflows from the northwest (Hegg et al. 1997). Airflows from the west and southwest pass over the large industrial and urban areas of the United States.

Since the airborne sampling and analysis techniques used in TARFOX and CLAMS were similar (and carried out by the same scientific team), we attribute the different aerosol characteristics encountered in these two field studies to the different origins of the sampled air.

\section{h. Sensitivity of results to hygroscopic growth}

Since the hygroscopic growth of the aerosol was not measured in this study, we assumed that the chemical composition and dry particle size distribution characteristics were similar to those measured in TARFOX and therefore used the parameterizations of hygroscopic
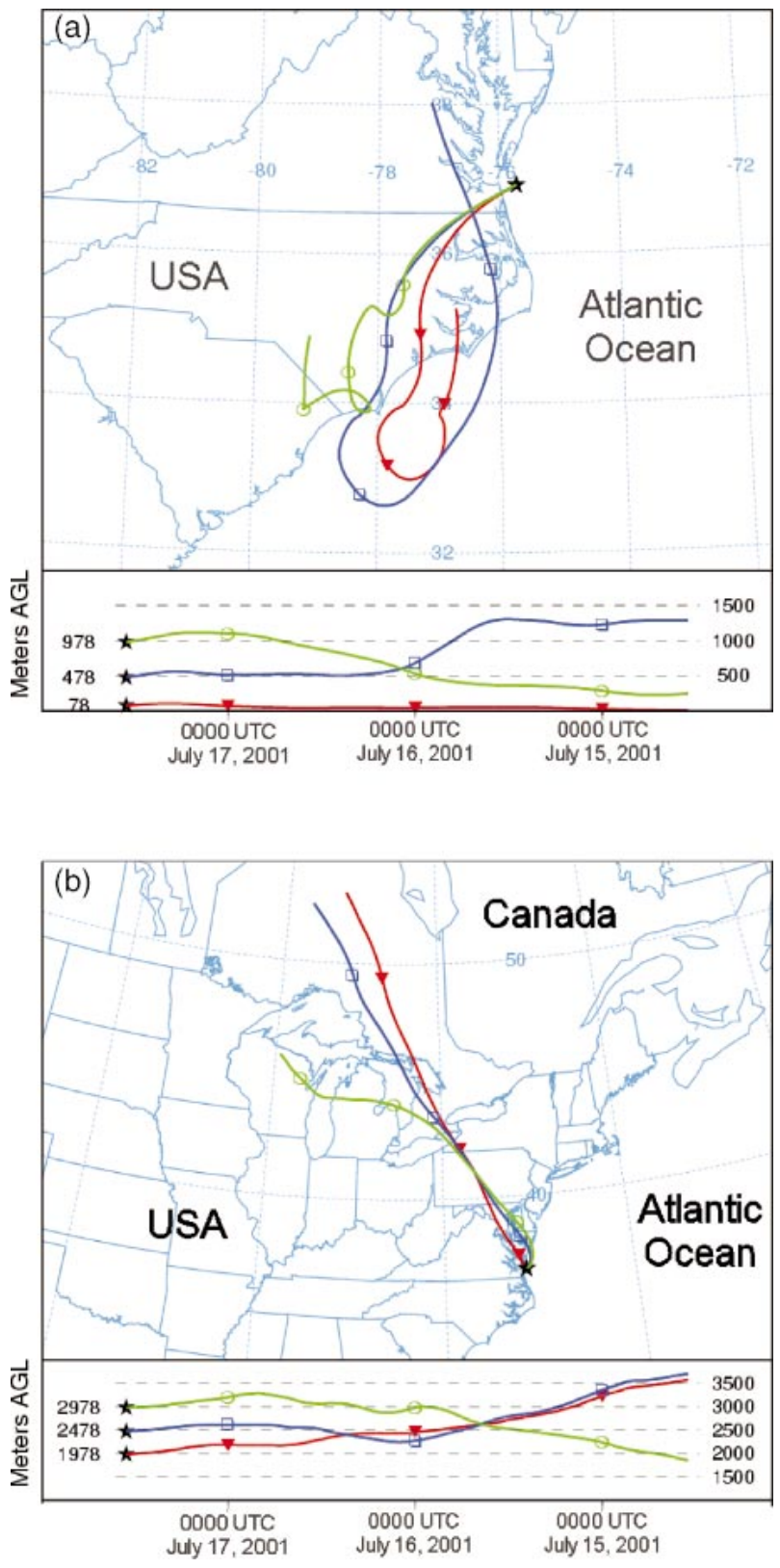

FIG. 8. Air parcel 72-h back trajectories from the location of the vertical profile obtained at 1300 UTC on $17 \mathrm{Jul} 2001$ (UW flight 1874) for (a) 100-, 500-, and 1000-m altitude and for (b) 1500-, 2200-, and 3000-m altitude. (Source: NOAA Hysplit model.)

growth described by Kotchenruther et al. (1999). Although the dry particle size distributions for particle diameters $<1 \mu \mathrm{m}$ (i.e., the accumulation mode) were similar in TARFOX and CLAMS, the dry sulfate contribution to the layer AOD in CLAMS was about twice that in TARFOX. The parcel back trajectories listed in Table 2 indicate that the aerosols sampled in CLAMS often came from the Canadian Atlantic coastal region or from sources in the Gulf of Mexico. As pointed out 
in section $4 \mathrm{~g}$, these back trajectories are different from those in TARFOX.

It could be that the results of Kotchenruther et al. (1999) underestimate the effect of RH for the aerosols measured in CLAMS. Assuming that Kotchenruther et al.'s results provide a lower bound for the RH growth in CLAMS, we can estimate an upper bound using $\mathrm{Li}$ et al.'s (2001) theoretical RH growth curve parameterizations for pure sulfate aerosols. We base our choice of the degree of acidity of the pure sulfate aerosol on a study by Brook et al. (1997), who found that sulfate aerosol acidity increased in maritime locations on the Canadian Atlantic coast compared to the generally neutralized sulfate aerosol encountered further inland. This was primarily due to the relative deficit of $\mathrm{NH}_{4}^{-}$sources in maritime locations. Therefore, to estimate an upper bound for the RH growth in CLAMS, we will assume that the particles in air parcels that passed over the interior of North America were primarily neutralized $\left(\mathrm{NH}_{4}\right)_{2} \mathrm{SO}_{4}$, and that the particles in parcels that passed over the maritime regions near North America were primarily of acidic $\mathrm{H}_{2} \mathrm{SO}_{4}$.

The upper bound to aerosol growth with increasing RH based on Li et al. (2001) and Brook et al. (1997) was applied to Eqs. (3) and (5), and to our calculations of the apportionment of AOD. Compared to (6), the equation for the relative error-weighted linear regression of $\tau_{\text {is }}$ versus $\tau_{\text {sun }}$ using this approach is

$$
\tau_{\text {is }}=(0.98 \pm 0.10) \tau_{\text {sun }}+(0.002 \pm 0.005) \text {, }
$$

where the linear correlation coefficient is $r=0.987$. This improves the rms difference between $\tau_{\text {is }}$ and $\tau_{\text {sun }}$ from $0.034 \pm 0.021$ to $0.028 \pm 0.018$. The average value for $\omega_{0}$ is $0.97 \pm 0.02$. The percentage contributions of sulfate, total carbon, condensed water, and absorption to the layer AOD are $26 \% \pm 11 \%, 16 \% \pm 6 \%$, $55 \% \pm 15 \%$, and $3 \% \pm 2 \%$, respectively, compared to $38 \% \pm 8 \%, 26 \% \pm 9 \%, 32 \% \pm 9 \%$, and $4 \% \pm 2 \%$. Thus, we may have underestimated $\tau_{\text {is }}$ by $\sim 20 \%$.

\section{Summary and conclusions}

In this study we have presented the results of airborne in situ measurements of aerosol properties off the East Coast of the United States obtained during the CLAMS field study in July-August 2001. Layer aerosol optical depths (AOD) were derived from vertical profiles of airborne in situ measurements of the light extinction coefficient and airborne sun photometer measurements. The rms difference between AOD derived from the in situ measurements and that measured by the sun photometer was $0.034 \pm 0.021$ at a wavelength of $550 \mathrm{~nm}$.

We have compared the results of this study to data collected using similar techniques and at nearly identical locations in July 1996 in the TARFOX field project. The measurements in the present study were generally obtained in relatively clean air that had recently passed over the Canadian Great Lakes or the Atlantic Ocean.
In TARFOX, on the other hand, the airflows were more commonly from industrial and urban areas immediately to the west of the study area, which generally resulted in much more polluted air than that encountered in CLAMS. For example, the layer AOD at $550 \mathrm{~nm}$ measured in TARFOX averaged $0.3 \pm 0.2$, whereas, in CLAMS the corresponding value was only $0.07 \pm 0.07$. The average single scattering albedo at ambient relative humidities for aerosol residing in the more polluted layers in CLAMS was $0.96 \pm 0.03$ at $550 \mathrm{~nm}$. In TARFOX, the corresponding value was 0.94 .

The dry mass scattering efficiencies for sulfate and total carbon derived from a multiple linear regression analysis of the data presented in this paper are $6.0 \pm$ $1.0 \mathrm{~m}^{2}\left(\mathrm{~g} \mathrm{SO}_{4}^{=}\right)^{-1}$ and $2.6 \pm 0.9 \mathrm{~m}^{2}(\mathrm{~g} \mathrm{C})^{-1}$, respectively. The corresponding values derived using the same method for TARFOX data were $3.2 \pm 1.3 \mathrm{~m}^{2}\left(\mathrm{~g} \mathrm{SO}_{4}^{=}\right)^{-1}$ and $6.8 \pm 1.1 \mathrm{~m}^{2}(\mathrm{~g} \mathrm{C})^{-1}$. One of the principle conclusions from the TARFOX study was that carbonaceous species made contributions of $40 \% \pm 15 \%$ to layer AOD in the lower atmosphere off the East Coast, with sulfate contributing only $19 \% \pm 8 \%$ (Hegg et al. 1997). In the present study, sulfate contributed $38 \% \pm 8 \%$ to the layer AOD, while carbonaceous species contributed $26 \% \pm$ 9\%. Assumed molecular forms of sulfate and carbonaceous species together accounted for $\sim 90 \%$ of the dry aerosol mass in TARFOX; in the present study they accounted for $94 \% \pm 6 \%$. The remaining major contribution to the AOD at $550 \mathrm{~nm}$ in the present study was due to condensed water $(32 \% \pm 9 \%)$, with absorbing aerosols contributing $4 \% \pm 2 \%$. In TARFOX, the contributions of condensed water and absorbing aerosols to the AOD were $35 \% \pm 23 \%$ and $7 \% \pm 4 \%$, respectively.

Comparisons of the results presented in this study with those from TARFOX suggest that the properties of the aerosol off the East Coast are highly dependent on airflow trajectories. The hygroscopic growth factor of the aerosol can have a significant effect on the AOD, but the average single scattering albedo appeared to be relatively insensitive to the hygroscopic growth factor over the range of RH values encountered in this study.

Acknowledgments. Thanks are due to all members of the UW Convair-580 flight crew and to the organizers of the Chesapeake Lighthouse and Aircraft Measurements for Satellites (CLAMS) field project where the measurements reported here were obtained. This research was supported by NASA Grants NAGS-10745 and NAGS-11665.

\section{REFERENCES}

Anderson, T. L., and J. A. Ogren, 1998: Determining aerosol radiative properties using the TSI 3563 integrating nephelometer. Aerosol Sci. Technol., 29, 57-69.

Bevington, P. R., and D. K. Robinson, 1992: Data Reduction and Error Analysis for the Physical Sciences. 2d ed. McGraw-Hill, $328 \mathrm{pp}$. 
Bond, T. C., T. L. Anderson, and D. Campbell, 1999: Calibration and intercomparison of filter-based measurements of visible light absorption by aerosols. Aerosol Sci. Technol., 30, 582-600.

Boucher, O., and T. L. Anderson, 1995: General circulation model assessment of the sensitivity of direct climate forcing by anthropogenic sulfate aerosols to aerosol size and chemistry. $J$. Geophys. Res., 100, 26 117-26 134.

Brook, J. R., and Coauthors, 1997: Temporal and spatial relationships in fine particle strong acidity, sulphate, PM10, and PM2.5 across multiple Canadian locations. Atmos. Environ., 31, 4223-4236.

Chan, Y. C., R. W. Simpson, G. H. Mctainsh, P. D. Vowles, D. D. Cohen, and G. M. Bailey, 1999: Source apportionment of visibility degradation problems in Brisbane (Australia) using the multiple linear regression techniques. Atmos. Environ., 33, 3237-3250.

Charlson, R. J., T. L. Anderson, and H. Rodhe, 1999: Direct climate forcing by anthropogenic aerosols: Quantifying the link between atmospheric sulfate and radiation. Contrib. Atmos. Phys., 72, 79-94.

Dubovik, O., A. Smirnov, B. N. Holben, M. D. King, Y. J. Kaufman, T. F. Eck, and I. Slutsker, 2000: Accuracy assessment of aerosol optical properties retrieved from Aerosol Robotic Network (AERONET) sun and sky radiance measurements. J. Geophys. Res., 105, 9791-9806.

Gao, S., D. A. Hegg, P. V. Hobbs, T. W. Kirchstetter, B. I. Magi, and M. Sadilek, 2003: Water-soluble organic components in aerosols associated with savanna fires in southern Africa: Identification, evolution, and distribution. J. Geophys. Res., 108, 8491, doi:10.1029/2002JD002324.

Hartley, S. W., P. V. Hobbs, J. L. Ross, P. B. Russell, and J. M. Livingston, 2000: Properties of aerosols aloft relevant to direct radiative forcing off the mid-Atlantic coast of the United States. J. Geophys. Res., 105, 9859-9885.

Haywood, J., and O. Boucher, 2000: Estimates of the direct and indirect radiative forcing due to tropospheric aerosols: A review. Rev. Geophys., 38, 513-545.

Hegg, D. A., T. Larson, and P. F. Yuen, 1993: A theoretical study of the effect of relative humidity on light scattering by tropospheric aerosols. J. Geophys. Res., 98, 18 435-18 439.

__ J. Jivingston, P. V. Hobbs, T. Novakov, and P. Russell, 1997: Chemical apportionment of aerosol optical depth off the midAtlantic coast of the United States. J. Geophys. Res., 102, 25 293-25 303.

Houghton, J. T., Y. Ding, D. J. Griggs, M. Noguer, P. J. van der Linden, and D. Xiaosu, Eds., 2001: Climate Change 2001: The Scientific Basis. Cambridge University Press, 896 pp.

Kato, S., and Coauthors, 2000: A comparison of the aerosol optical thickness derived from ground-based and airborne measurements. J. Geophys. Res., 105, 14 701-14 717.

Kawamura, K., and I. R. Kaplan, 1987: Motor exhaust emissions as a primary source for dicarboxylic acids in Los Angeles ambient air. Environ. Sci. Technol., 21, 105-110.

Kirchstetter, T. W., T. Novakov, P. V. Hobbs, and B. Magi, 2003: Airborne measurements of carbonaceous aerosols in southern Africa during the dry, biomass burning season. J. Geophys. Res., 108, 8476, doi:10.1029/2002JD002171.

Kotchenruther, R. A., P. V. Hobbs, and D. A. Hegg, 1999: Humidification factors for atmospheric aerosols off the mid-Atlantic coast of the United States. J. Geophys. Res., 104, 2239-2251.

Li, J., J. G. D. Wong, J. S. Dobbie, and P. Chylek, 2001: Parame- terization of the optical properties of sulfate aerosols. J. Atmos. Sci., 58, 193-209.

Liousse, C., J. E. Penner, C. Chuang, J. J. Walton, H. Eddleman, and H. Cachier, 1996: A global three-dimensional model study of carbonaceous aerosols. J. Geophys. Res., 101, 19 411-19 432.

Magi, B. I., and P. V. Hobbs, 2003: Effects of humidity on aerosols in southern Africa during the biomass burning season. J. Geophys. Res., 108, 8495, doi:10.1029/2002JD002144.

, - B. Bchmid, and J. Redemann, 2003: Vertical profiles of light scattering, light absorption and single-scattering albedo during the dry, biomass burning season in southern Africa and comparisons of in-situ and remote sensing measurements of aerosol optical depth. J. Geophys. Res., 108, 8504, doi:10.1029/ 2002JD002361.

Penner, J. E., C. C. Chuang, and K. Grant, 1998: Climate forcing by carbonaceous and sulfate aerosols. Climate Dyn., 14, 839-851.

Redemann, J., P. B. Russell, and P. Hamill, 2001: Dependence of aerosol light absorption and single-scattering albedo on ambient relative humidity for sulfate aerosols with black carbon cores. J. Geophys. Res., 106, 27 485-27 495.

_ - S. Masonis, B. Schmid, T. Anderson, P. Russell, J. Livingston, O. Dubovik, and A. Clarke, 2003: Clear-column closure studies of aerosols and water vapor aboard the NCAR C-130 in ACEAsia 2001. J. Geophys. Res., 108, 8655, doi:10.1029/ 2003JD003442.

- and Coauthors, 2005: Suborbital measurements of spectral aerosol optical depth and its variability at subsatellite grid scales in support of CLAMS 2001. J. Atmos. Sci., 62, 993-1007.

Remer, L. A., S. Gassó, D. A. Hegg, Y. J. Kaufman, and B. N. Holben, 1997: Urban/industrial aerosol: Ground-based Sun/sky radiometer and airborne in situ measurements. J. Geophys. Res., 102, $16849-16859$.

Schmid, B., and Coauthors, 2000: Clear sky closure studies of lower tropospheric aerosol and water vapor during ACE 2 using airborne sunphotometer, airborne in-situ, space-borne, and groundbased measurements. Tellus, B52, 568-593.

_ , and Coauthors, 2003: Coordinated airborne, spaceborne, and ground-based measurements of massive, thick aerosol layers during the dry season in southern Africa. J. Geophys. Res., 108, 8496, doi:10.1029/2002JD002297.

Sempere, R., and K. Kawamura, 1996: Low molecular weight dicarboxylic acids in related polar compounds in the remote marine rain samples collected from western Pacific. Atmos. Environ., 30, 1609-1619.

Shekar Reddy, M., and C. Venkataraman, 2000: Atmospheric optical and radiative effects of anthropogenic aerosol constituents from India. Atmos. Environ., 34, 4511-4523.

Turpin, B. J., and H. J. Lim, 2001: Species contributions to PM2.5 mass concentrations: Revisiting common assumptions for estimating organic mass. Aerosol Sci. Technol., 35, 602-610.

Vasconcelos, L. A. de P., E. S. Macias, P. H. McMurray, B. J. Turpin, and W. H. White, 2001: A closure study of extinction apportionment by multiple regression. Atmos. Environ., 35, 151-158.

White, W. H., 1990: The chemical composition of fine particles. Visibility: Existing and Historical Conditions-Causes and Effects, J. C. Trijonis, Ed., U.S. National Acid Precipitation Assessment Program, 90-94.

Yokouchi, Y., and Y. Ambe, 1986: Characterization of polar organics in airborne particulate matter. Atmos. Environ., 20, 1727-1734.

Zhang, X., B. J. Turpin, P. H. McMurry, S. V. Hering, and M. R. Stolzenburg, 1994: Mie theory evaluation of species contributions to 1990 wintertime visibility reduction in the Grand Canyon. J. Air Waste Manage., 44, 153-162. 